\title{
Effects of Supply Parameters of Stratum Ventilation on Energy Utilization Efficiency and Indoor Thermal Comfort: A Computational Approach
}

\author{
Lina Zhang $\mathbb{D}^{1},{ }^{1}$ Yanhui Mao, ${ }^{1}$ Qiu Tu, ${ }^{1}$ Xiaogang $W u,{ }^{1}$ and Lingyu Tan ${ }^{2}$ \\ ${ }^{1}$ School of Civil and Transportation Engineering, Ningbo University of Technology, Ningbo, China \\ ${ }^{2}$ Zhejiang Dehong Electromechanical Technology Co., Ltd., Jiaxing, China \\ Correspondence should be addressed to Lina Zhang; zhangln881013@126.com
}

Received 3 January 2021; Revised 10 March 2021; Accepted 29 March 2021; Published 8 April 2021

Academic Editor: Ahmad Zeeshan

Copyright (c) 2021 Lina Zhang et al. This is an open access article distributed under the Creative Commons Attribution License, which permits unrestricted use, distribution, and reproduction in any medium, provided the original work is properly cited.

\begin{abstract}
Stratum ventilation shows the significant potential on energy conservation and indoor thermal comfort under cooling applications. Yet, only limited researches focus on the thermal performance of stratum ventilation under heating condition. The heating and cooling operation characteristic of stratum ventilation is different due to the distinct airflow characteristics. Therefore, this paper investigated the parameters that affect energy utilization efficiency and indoor thermal comfort under heating condition served by stratum ventilation via CFD simulations approach. The supply air parameters included temperature, airflow rate, angle, and return air outlet positions. The evaluation indicators adopt ventilation effectiveness and effective draft temperature (EDT) for assessing the energy utilization efficiency and indoor thermal comfort served by stratum ventilation under heating condition. The results demonstrated that, under the heating mode of stratum ventilation, different effects on the thermal performance were made by the mentioned parameters. The ventilation effectiveness was higher when the air supply temperature is $26^{\circ} \mathrm{C}$, airflow rate is 7 air change per hour $(\mathrm{ACH})$, and the air supply angle is $45^{\circ}$. The EDT range of the occupied zone is closest to zero $\mathrm{K}$ when the air supply temperature is $28^{\circ} \mathrm{C}$, airflow rate is $12(\mathrm{ACH})$, and the air supply angle is $60^{\circ}$. The related conclusions obtained from this study provide the theoretical basis for the stratum ventilation design and promote its heating application.
\end{abstract}

\section{Introduction}

Energy utilization efficiency and indoor thermal comfort are the main evaluation indicators for the Heating Ventilation and Air Conditioning (HVAC) system. Up to now, $40 \%$ of the world energy consumption has been consumed by building energy consumption [1]. And air conditioning accounts for around $40 \%$ of the total building energy consumption $[2,3]$. Therefore, energy consumption reduction for air conditioning has become an extremely urgent task. It is reported that elevating indoor temperature in summer and decreasing indoor temperature in winter are a necessary mean in reducing the energy consumption of air conditioners. Hence, 195 countries agreed to enhance the indoor temperature by $1.5^{\circ} \mathrm{C}$ for air conditioner energy reduction in the Paris Agreement [2]. Moreover, most people are recorded to spend the most time $(>85 \%)$ in the enclosed space with air conditioning, so poor indoor air quality can significantly decrease the life quality and work efficiency of building occupants [4]. It demonstrates that improving indoor air quality is another significant task for the HVAC systems. As the recently proposed mechanical ventilation method, stratum ventilation can be seen as a potential solution for these two problems [5].

The fresh air of stratum ventilation is supplied through the inlets installed at the midlevel of the walls. Hence, it can make the fresh air directly reach the breathing zone. Hence, the air supply path can be greatly shortened. According to the related studies, relative to mixing ventilation and displacement ventilation, the stratum ventilation thermal neutral temperature can be increased $2.5^{\circ} \mathrm{C}$ and $2.0^{\circ} \mathrm{C}$, respectively [6]. Therefore, stratum ventilation performs better 
in thermal comfort and healthy environment. Stratum ventilation used for space cooling applications is widely researched in the existing studies due to its air distribution advantages [7]. The research results pointed out that stratum ventilation can provide higher thermal comfort and lower contaminant concentrations in the breathing zone with lower system energy consumption $[8,9]$. Stratum ventilation control method and optimization design in the cooling condition are also the research focus for energy conservation [10].

In the actual application, there are various factors that influence the thermal performance of stratum ventilation, such as temperature, airflow rate, the air inlet angle, and the return air outlet positions $[6,11-13]$. In the cooling condition, the angle of $0^{\circ}$ is generally suggested for preventing the cold air subsidence caused by thermal buoyancy [14]. As for the heating applications, the warm air will rise under the impact of thermal buoyancy. Therefore, there will be an obvious difference on the operation parameters for stratum ventilation between heating and cooling conditions, causing the air supply angle to become a vital factor impacting the ventilation thermal performance for space heating [13]. Hence, the existing researches on optimal parameters of stratum ventilation under cooling condition cannot be used in space heating.

For the southern region of China with heating requirement, it is most suitable to employ efficient mechanical ventilation in space heating. As for stratum ventilation, the warm air can be directly supplied into the occupied zone to reduce the vertical temperature gradient $[15,16]$. Stratum ventilation as a recently proposed ventilation method is relatively new. And there are only a few studies on its heating application. The current related studies mainly focus on multicriteria performance optimization [17], the effects of operation parameters on the performance indices [18], and the performance comparison of stratum ventilation with other ventilation methods under heating mode [19]. However, researching the impact of supply parameters on ventilation effectiveness (Et) and effective draft temperature (EDT) to propose the optimal supply air parameters for stratum ventilation under heating mode is scarce, which will be the a strong supplement to the current research for the better application of stratum ventilation in the future. Hence, in this paper, a typical office is used to study the optimal parameters based on the flow characteristics under heating condition. Through the combination of experiment and numerical simulation, the impacts of supply air parameters including temperature, airflow rate, angle, and return air outlet position on the stratum ventilation thermal performance under heating condition are assessed by Et and EDT. The related conclusions obtained from this research provide the theoretical basis for the stratum ventilation design and promote its heating application.

\section{Methodology}

\subsection{Experimental Setup}

2.1.1. Test Procedure. The experiment was conducted in a test chamber measuring $6 \mathrm{~m} \times 4 \mathrm{~m} \times 3.5 \mathrm{~m}$ under a variation from -10 to $-3^{\circ} \mathrm{C}$ of the ambient air temperature. The treated air was supplied by the air inlets (S1-S4) with a size of $0.3 \mathrm{~m} \times 0.3 \mathrm{~m}$. The air inlets were installed at $1.2 \mathrm{~m}$ height of the wall. During the experiment, only S1 and S3 were opened. And the return air outlets were located on the ceiling. Variable speed fans were employed to vary the supply air volume.

The internal load of this chamber is set as six occupants and two incandescent lamps. The sedentary occupant was simulated by a cuboid thermal manikin whose size is $0.4 \mathrm{~m} \times 0.25 \mathrm{~m} \times 1.2 \mathrm{~m}$. And a $100 \mathrm{~W}$ light bulb was set in the cuboid to represent the occupant's thermal radiation and convection effects. The method has been commonly used to consider the occupant impact on the indoor thermal environment [20]. The power of the two incandescent lamps installed on one side of the wall is also $100 \mathrm{~W}$. Supply air temperature and velocity were measured by dry bulb temperature and velocity sensors installed on the measurement plumb lines at the heights of $0.1 \mathrm{~m}, 0.6 \mathrm{~m}, 1.1 \mathrm{~m}, 1.4 \mathrm{~m}, 2.1 \mathrm{~m}$, and $2.8 \mathrm{~m}$, respectively.

2.1.2. Measurement Instrumentation. In this study, T-thermocouple $\left( \pm 0.3^{\circ} \mathrm{C}\right.$ accuracy) was used to measure the temperature, and hot-wire anemometer (Testo-480) $( \pm 0.05 \mathrm{~m} / \mathrm{s}$ accuracy) was used to measure the velocity. Kline and McClintock are introduced to conduct the error analysis [21]. The relative uncertainty equation is provided as follows:

$$
\frac{\Delta R}{R}=\left[\sum_{i=1}^{n}\left(\frac{\Delta X_{i}}{X_{i}}\right)^{2}\right]^{1 / 2},
$$

where $X$ is the independent variant. Through calculation, the temperature and velocity measurement accuracy are calculated as $0.08 \%$ and $0.25 \%$, respectively.

2.2. CFD Simulation. With the characteristics of less cost and time consuming, computational fluid dynamics (CFD) is commonly employed to simulate indoor thermal environment [22]. Through years of development, CFD simulation can predict indoor velocity distribution, indoor temperature distribution, and indoor air quality accurately [23-25].

Based on the related study [26], a typical size of an office model can be used to investigate the airflow characteristics under various ventilation methods. The related research [27] indicates that it is suitable to simulate the air temperature and airflow by using the standard $k-\varepsilon$ two-equation model. Hence, considering the higher accuracy and calculation efficiency, the standard $k-\varepsilon$ model was introduced in this study. Discrete ordinates radiation model was introduced to consider the radiative heat transfer between surfaces. Boussinesq model was used to compute the buoyancy effect [28]. The air in the calculation area was assumed to be incompressible Newtonian fluid acting as a constant flow. To consider the ambient temperature impacts on the indoor environment, the exterior walls were set as constant temperature [29]. The 3D model is presented in Figure 1, and the detailed boundary conditions of experimental and numerical are shown in Table 1. 


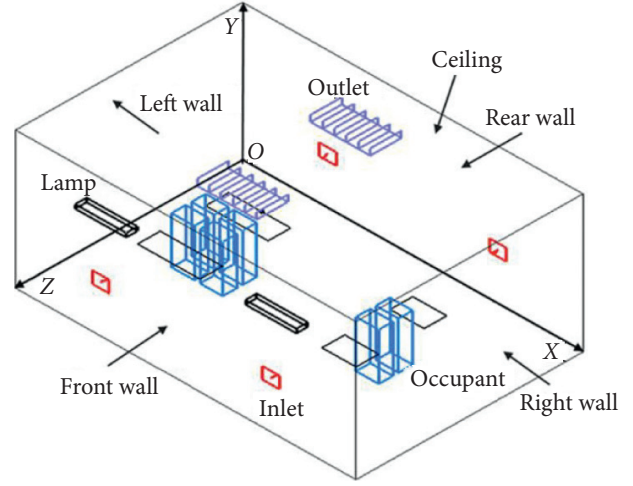

(a)

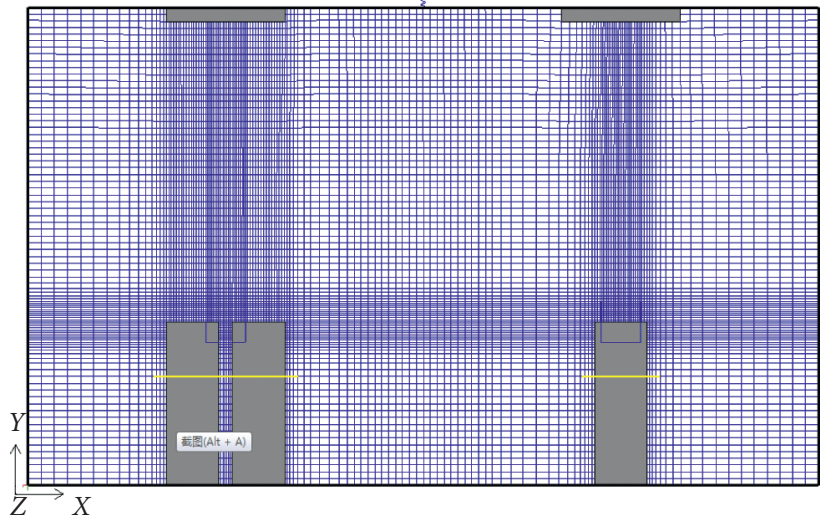

(b)

Figure 1: CFD 3D model (a) and mesh of $Z=2.0 \mathrm{~m}(\mathrm{~b})$.

TABLE 1: Detailed information of the boundary conditions.

\begin{tabular}{|c|c|c|c|}
\hline & Boundary condition & Experimental parameter & Simulated parameter \\
\hline Supply air inlet & Uniform velocity & $27.0^{\circ} \mathrm{C}, 1.30 \mathrm{~m} / \mathrm{s}$ & $26-29^{\circ} \mathrm{C}, 0.63-1.30 \mathrm{~m} / \mathrm{s}$ \\
\hline Return air outlet & Free pressure & - & - \\
\hline Exterior wall & Constant temperature & $13.0^{\circ} \mathrm{C}$ & $10.0-17.0^{\circ} \mathrm{C}$ \\
\hline Floor and ceiling & Adiabatic & - & - \\
\hline Occupants & Constant heat flux & $100 \mathrm{~W} /$ person & $100 \mathrm{~W} /$ person \\
\hline Lights & Constant heat flux & $100 \mathrm{~W} /$ one lamp & $100 \mathrm{~W} /$ one lamp \\
\hline
\end{tabular}

To obtain the results accurately and in time-saving manner, the grid independence test based on the sufficient number of elements was performed. The average temperature at the height of $1.1 \mathrm{~m}$ calculated by coarse grid, moderate grid, and fine grid was compared and presented in Table 2. Finally, Mesh 2 was selected due to less than $5 \%$ of the maximum relative error compared to Mesh 3. Moreover, the girds used in this study are all hexahedral and the mesh quality is one.

2.3. Cases Studied. The purpose of cases is to explore the effects of supply air parameters including temperature, airflow rate, angle, and return air outlet locations on the stratum ventilation thermal performance, respectively. To conduct the univariate analysis, the control variable method was adopted in this study. When discussing the effect of one of the variables, the others are left unchanged. Each parameter with four variations was discussed in the simulation, i.e., $26.0-29.0^{\circ} \mathrm{C}$ for the supply air temperature (cases 1-4); 7-15 ACH for the supply airflow rate (cases $5-8$ ); $15^{\circ} \sim 60^{\circ}$ for the supply air angle (cases $9-12$ ). And four return air outlet positions are studies in cases 13-16: on the ceiling, at the same level opposite to the supply air inlets, on the opposite wall of the supply air inlets with $0.5 \mathrm{~m}$ height above the floor, and on the same wall of the supply air inlets with $0.5 \mathrm{~m}$ height above the floor. The detailed input parameters of the studied case are presented in Table 3.

2.4. Ventilation Performance Evaluation Index. Ventilation effectiveness and effective draft temperature are employed in this study to appraise stratum ventilation on the performance of thermal characteristics.
TABLE 2: Gird independence test for selection of three densities of mesh.

\begin{tabular}{lccc}
\hline Mesh & $\begin{array}{c}\text { Number of } \\
\text { gird nodes }\end{array}$ & $\begin{array}{c}\text { Simulated } \\
\text { temperature }\left({ }^{\circ} \mathrm{C}\right)\end{array}$ & $\begin{array}{c}\text { Maximum relative error } \\
\text { in computing values of } \\
\text { temperature compared to } \\
\text { the previous mesh values } \\
(\%)\end{array}$ \\
\hline 1 & 1654610 & 19.65 & - \\
2 & 2404324 & 21.25 & 8.14 \\
3 & 3926751 & 21.11 & 0.66 \\
\hline
\end{tabular}

2.4.1. Ventilation Effectiveness. A larger $E_{\mathrm{t}}$ indicates a higher energy utilization efficiency. Less warm supply air is needed to achieve the target temperature in the occupied zone. It is calculated through the following equation [30]:

$$
E_{\mathrm{t}}=\frac{\left(T_{\mathrm{e}}-T_{\mathrm{s}}\right)}{\left(T_{\mathrm{oz}}-T_{\mathrm{s}}\right)},
$$

where $E_{\mathrm{t}}$ is the ventilation effectiveness; $T_{\mathrm{e}}$ is the exhaust air temperature, ${ }^{\circ} \mathrm{C} ; T_{\mathrm{s}}$ is the supply air temperature, ${ }^{\circ} \mathrm{C}$; and $T_{\mathrm{oz}}$ is the average occupied zone temperature, ${ }^{\circ} \mathrm{C}$.

2.4.2. Effective Draft Temperature (EDT). Lin recently put forward a new calculation formula of EDT for stratum ventilation, which has been confirmed to be reliable and straightforward to assess the thermal comfort performance [31]. Similar to the calculation parameters of PMV, EDT can comprehensively consider the effect of indoor air temperature, radiant temperature, velocity, humidity, and human 
TABLE 3: Studied cases of parameters.

\begin{tabular}{|c|c|c|c|c|c|c|}
\hline Case & $\mathrm{ACH}$ & $T_{\mathrm{s}}\left({ }^{\circ} \mathrm{C}\right)$ & Supply air angle $\left({ }^{\circ}\right)$ & Air outlet location & $\mathrm{Q}\left(\mathrm{m}^{3} / \mathrm{s}\right)$ & $T_{\mathrm{n}}\left({ }^{\circ} \mathrm{C}\right)$ \\
\hline 1 & \multirow{4}{*}{15} & 26.0 & \multirow{4}{*}{ 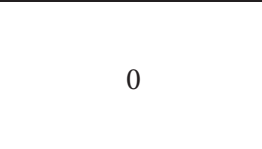 } & \multirow{4}{*}{ Ceiling-counted } & \multirow{4}{*}{0.468} & \multirow{4}{*}{21.0} \\
\hline 2 & & 27.0 & & & & \\
\hline 3 & & 28.0 & & & & \\
\hline 4 & & 29.0 & & & & \\
\hline 5 & 7 & \multirow{4}{*}{27.0} & \multirow{4}{*}{0} & \multirow{4}{*}{ Ceiling-counted } & 0.220 & \multirow{4}{*}{21.0} \\
\hline 6 & 10 & & & & 0.313 & \\
\hline 7 & 12 & & & & 0.374 & \\
\hline 8 & 15 & & & & 0.468 & \\
\hline 9 & \multirow{4}{*}{10} & \multirow{4}{*}{27.0} & 15 & \multirow{4}{*}{ Ceiling-counted } & \multirow{4}{*}{0.313} & \multirow{4}{*}{21.0} \\
\hline 10 & & & 30 & & & \\
\hline 11 & & & 45 & & & \\
\hline 12 & & & 60 & & & \\
\hline 13 & \multirow{4}{*}{10} & \multirow{4}{*}{27.0} & \multirow{4}{*}{0} & Ceiling-counted & \multirow{4}{*}{0.313} & \multirow{4}{*}{21.0} \\
\hline 14 & & & & The same level in the opposite direction of the air inlet & & \\
\hline 15 & & & & The bottom level in the opposite direction of the air inlet & & \\
\hline 16 & & & & The bottom level in the opposite direction of the air inlet & & \\
\hline
\end{tabular}

Q: air supply volume; $T_{\mathrm{s}}$ : supply air temperature; $T_{\mathrm{n}}$ : nominal room temperature; $\mathrm{ACH}$ : air change rate per hour.

activity on the thermal comfort. The corresponding calculation equation is shown as [32]

$$
\operatorname{EDT}=\left(T_{\mathrm{oz}}-T_{\mathrm{c}}\right)-\left(v_{\mathrm{x}}-1.1\right)
$$

where $T_{\mathrm{c}}$ is the mean dry-bulb temperature of the space, ${ }^{\circ} \mathrm{C}$; $v_{\mathrm{x}}$ is the local velocity, $\mathrm{m} / \mathrm{s}$. The thermal environment is deemed to be satisfactory when EDT value is within the range of $-1.2 \mathrm{~K}$ and $+1.2 \mathrm{~K}$.

\section{Results}

3.1. Model Validation. Once the Airpak model built, a validation is also necessary to investigate the simulation accuracy. The simulation of the airflow and temperature distribution for a typical thermal scenario was conducted, and the results were compared with the experimental results. In the model validation, the supply air temperature was selected to be $27.0^{\circ} \mathrm{C}$ and the air change per hour was set as $15 \mathrm{ACH}$ (c.f. case 2 in Table 3). The boundary conditions that are employed in this numerical model are set as same as those in the experiment. The heat sources consisted of occupants and lamps. Velocities and temperatures of five typical positions at $1.1 \mathrm{~m}$ were calculated and measured. Differences between the numerical and experimental values are shown in Figure 2. It can be seen that the simulated values (both velocity and temperature) mostly match the measured ones. Maximum, minimum, and average temperature difference values were $0.4,-0.2$, and $0.1^{\circ} \mathrm{C}$, respectively. And those between the experimental and simulated velocities were $0.07,-0.01$, and $0.02 \mathrm{~m} / \mathrm{s}$, respectively.

To quantitatively describe the model performance, four statistical methods were introduced here as well $[33,34]$. Among them, the mean absolute error (MAE) can be defined as follows:

$$
\operatorname{MAE}=\frac{1}{p} \sum_{i=1}^{p}\left|x_{i}-y_{i}\right|,
$$

where $x_{i}$ represents the measurements, $y_{i}$ represents the numerical values, and $p$ is the total experimental test points.
Equation (5) shows the definition of the mean absolute percentage error (MAPE):

$$
\text { MAPE }=\frac{1}{p} \sum_{i=1}^{p} \frac{\left|x_{i}-y_{i}\right|}{\left|x_{i}\right|} \times 100 \% .
$$

The root-mean-square error (RMSE) is as

$$
\mathrm{RMSE}=\sqrt{\frac{1}{p} \sum_{i=1}^{p}\left|x_{i}-y_{i}\right|^{2}}
$$

For the index of agreement (IA), it is calculated as follows:

$$
\mathrm{IA}=1-\frac{\sum_{i=1}^{p}\left(x_{i}-y_{i}\right)^{2}}{\sum_{i=1}^{p}\left(\left|y_{i}-x_{m}\right|+\left|x_{i}-x_{m}\right|\right)^{2}}
$$

When the result value is 0 for the MAE, MAPE, and RMSE and 1 for IA, it shows that the simulation results agree well with the measurements. Table 4 provides the calculation results for the temperature and velocity. MAE, MAPE, and RMSE values of velocity are $0.023 \mathrm{~m} / \mathrm{s}, 0.097 \%$, and $0.001 \mathrm{~m} /$ $\mathrm{s}$, respectively, and those of temperature are $0.05^{\circ} \mathrm{C}, 0.01 \%$, and $0.05^{\circ} \mathrm{C}$, respectively, which are close to 0 . The IA value of temperature is 0.97 and that of velocity is 0.876 ; both are close to unity. The simulation results are basically consistent with the experimental results, which indicates that the numerical model is reliable to calculate different air parameters of stratum ventilation in various cases.

\subsection{Effect of Supply Air Parameters on Ventilation Effectiveness}

3.2.1. Supply Air Temperature. In this study, ventilation effectiveness is applied as an index to access the energy utilization efficiency. As known to all, the higher the ventilation effectiveness, the better the energy efficiency. Figure 3 shows the calculation and fitting curves of the average ventilation 


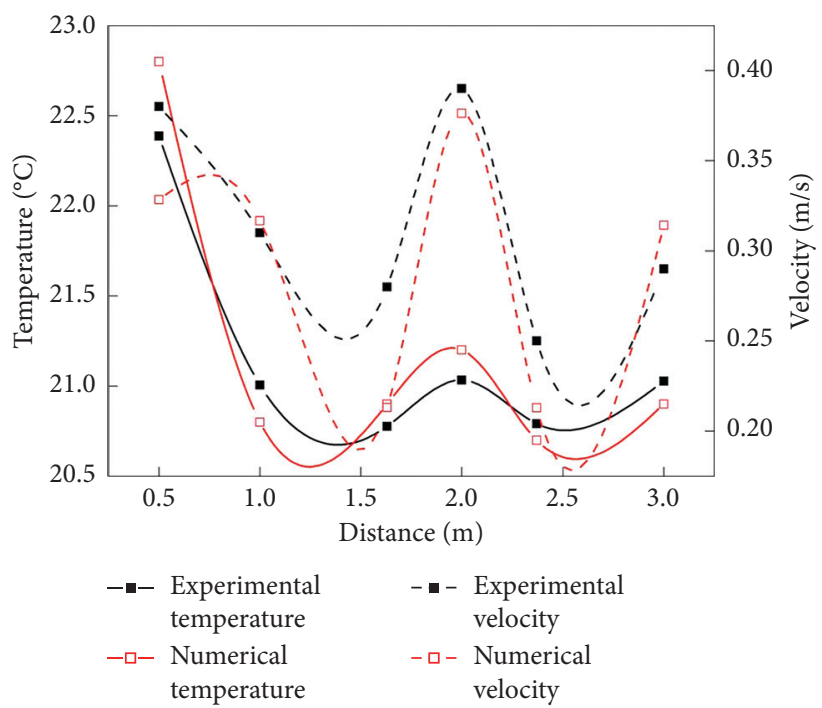

Figure 2: Dissimilarities between temperature and velocity experimental and numerical results.

TABLE 4: The detailed information of model performance.

\begin{tabular}{lcc}
\hline Metric & Temperature & Velocity \\
\hline MAE & $0.05^{\circ} \mathrm{C}$ & $0.023 \mathrm{~m} / \mathrm{s}$ \\
MAPE & $0.01 \%$ & $0.097 \%$ \\
RMSE & $0.05^{\circ} \mathrm{C}$ & $0.001 \mathrm{~m} / \mathrm{s}$ \\
IA & 0.97 & 0.876 \\
\hline
\end{tabular}

effectiveness among the occupied zones at different supply air temperatures. According to the related research [18], polynomial can be applied to the fitting in the study on stratum ventilation. Based on this, the fitting formulae are as follows:

$$
\begin{aligned}
& E t_{26}=1.005+0.236 h-0.06 h^{2}, \\
& E t_{27}=0.81+0.186 h-0.05 h^{2}, \\
& E t_{28}=0.825+0.187 h-0.05 h^{2}, \\
& E t_{29}=0.913+0.213 h-0.05 h^{2},
\end{aligned}
$$

where $E t_{26}$ is the ventilation effectiveness at supply air temperature of $26^{\circ} \mathrm{C}$; $E t_{27}$ is the ventilation effectiveness at the supply air temperature of $27^{\circ} \mathrm{C} ; E t_{28}$ is the ventilation effectiveness at the supply air temperature of $28^{\circ} \mathrm{C}$; $E t_{29}$ is the ventilation effectiveness at the supply air temperature of $29^{\circ} \mathrm{C}$; $h$ is the height, $m$.

$\gamma$ is introduced for the propose of comparing the performance under the four supply air temperatures, which is defined as follows:

$$
\gamma=\frac{\overline{E t_{x}}}{\overline{E t}}=\frac{\int_{0}^{h_{0}} E t_{x} / h_{0}}{\int_{0}^{h_{0}} E t / h_{0}},
$$

where $\overline{E t_{x}}$ is the mean ventilation effectiveness in any case among the breathing zones; $\overline{E t}$ is the mean ventilation effectiveness in benchmark case among the breathing zones; $h_{0}$ is the height of the breathing level, $m$. In this study, $h_{0}$ is set as $1.1 \mathrm{~m} . \gamma$ is the ratio of $\overline{E t_{x}}$ to $\overline{E t}$. Setting $\overline{E t_{26}}$ as the base value, it is calculated that $\overline{E t_{26}}$ is $1.11, \overline{E t_{27}}$ is $0.892, \overline{E t_{28}}$ is 0.908 , and $\overline{E t_{29}}$ is 1.01 . Hence, $\gamma_{27-26}$ is $0.804, \gamma_{28-26}$ is 0.818 , and $\gamma_{29-26}$ is 0.918 .

The ventilation effectiveness is affected synthetically by the thermal buoyancy and average temperature among the occupied zones. When the supply air temperature is $26^{\circ} \mathrm{C}$, more heat would stay in the occupied zone contributing by less thermal buoyancy, thus leading to higher ventilation effectiveness. Since the air inlet of the stratum ventilation is located at the middle level of the side wall, the supply air temperature of $29^{\circ} \mathrm{C}$ leads the temperature near the supply air inlet to become higher and then resulting in a higher average temperature among the occupied zones compared with that under $27^{\circ} \mathrm{C}$ and $28^{\circ} \mathrm{C}$. However, thermal buoyancy plays a dominant role in these two mechanisms. Hence, the ventilation effectiveness under $26^{\circ} \mathrm{C}$ of the supply air temperature is the highest. And the ventilation effectiveness under $26^{\circ} \mathrm{C}$ of the supply air temperatures being $27^{\circ} \mathrm{C}, 28^{\circ} \mathrm{C}$, and $29^{\circ} \mathrm{C}$ is lower.

3.2.2. Airflow Rate. Similarly, to compare the ventilation efficiency at different airflow rates, Figure 4 fits the ventilation efficiency at different heights. The formulae are as follows:

$$
\begin{aligned}
E t_{7} & =0.955+0.097 h-0.026 h^{2}, \\
E t_{10} & =0.879+0.176 h-0.05 h^{2}, \\
E t_{12} & =0.911+0.158 h-0.04 h^{2}, \\
E t_{15} & =0.912+0.128 h-0.03 h^{2},
\end{aligned}
$$




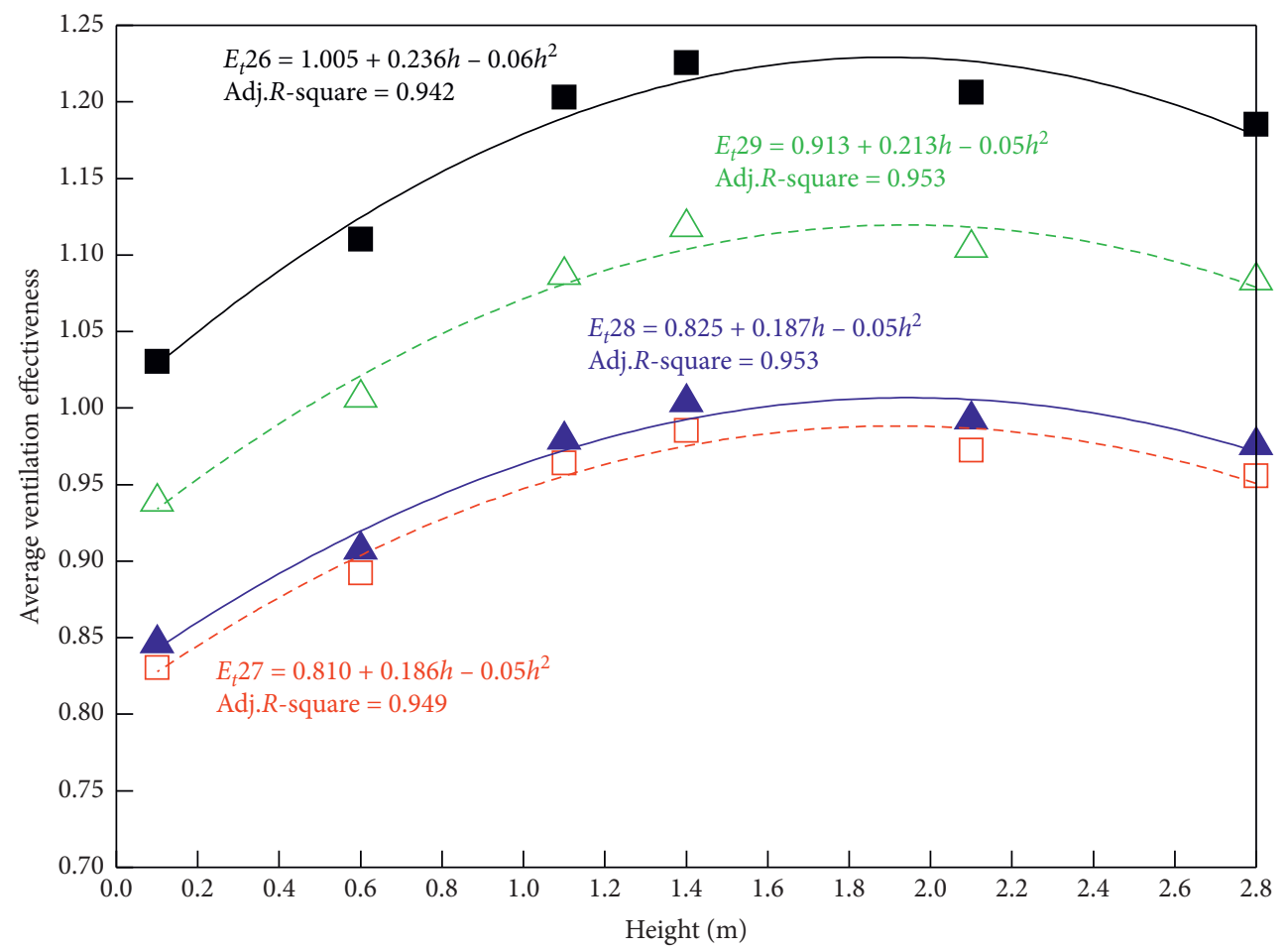

26
$\square \quad 27$
$\Delta \quad 28$
$\triangle \quad 29$

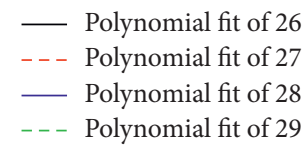

FIgURE 3: Average ventilation effectiveness at different supply air temperatures.

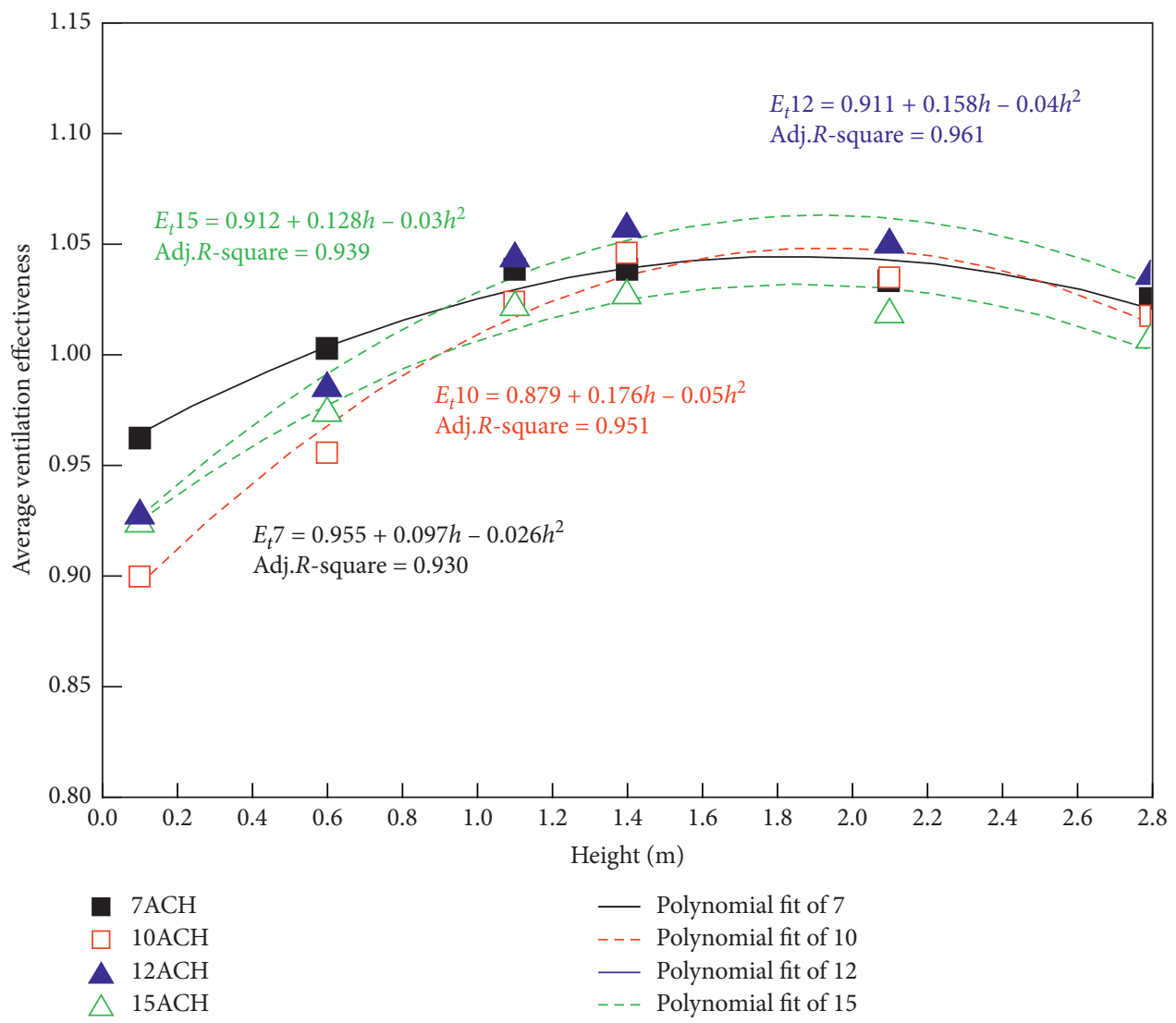

FIgURE 4: Average ventilation effectiveness at different airflow rates $(\mathrm{ACH})$. 


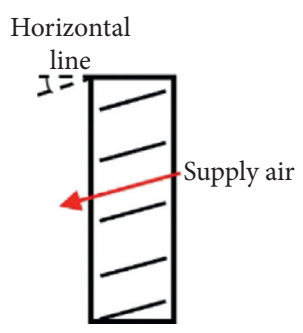

(a)

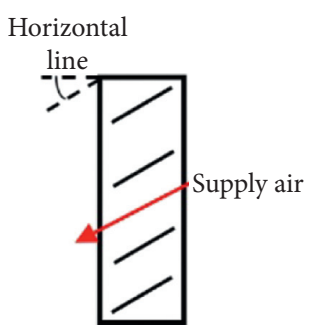

(b)

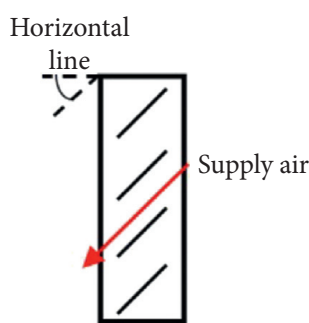

(c)

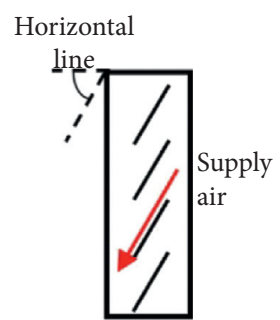

(d)

FIGURE 5: The supply vane angle schematic diagram.

where $E t_{7}$ is the ventilation effectiveness for the $7 \mathrm{ACH}$ case; $E t_{10}$ is the ventilation effectiveness of $10 \mathrm{ACH} ; E t_{12}$ is the ventilation effectiveness of $12 \mathrm{ACH} ; E t_{15}$ is the ventilation effectiveness of $15 \mathrm{ACH}$. $\overline{E t_{7}}$ is set as the base value. It can be calculated that $\overline{E t_{7}}$ is $0.998, \overline{E t_{10}}$ is $0.956, \overline{E t_{12}}$ is $0.982, \overline{E t_{15}}$ is $0.970, \gamma_{10-7}$ is $0.958, \gamma_{12-7}$ is 0.984 , and $\gamma_{15-7}$ is 0.972 . It indicates that the ventilation effectiveness is the highest at $7 \mathrm{ACH}$.

3.2.3. Supply Air Angle. The schematic diagram of supply vane angle discussed in this study is provided as Figure 5.

Using the same method, as shown in Figure 6, the fitted formulae of the ventilation effectiveness for different angles are given as follows:

$$
\begin{aligned}
& E t_{15}=0.932+0.131 h-0.035 h^{2}, \\
& E t_{30}=0.869+0.109 h-0.03 h^{2}, \\
& E t_{45}=0.976+0.119 h-0.03 h^{2}, \\
& E t_{60}=0.997+0.073 h-0.02 h^{2},
\end{aligned}
$$

where $E t_{15}$ is the ventilation effectiveness for the supply air angle of $15^{\circ} ; E t_{30}$ is the ventilation effectiveness of supply air angle of $30^{\circ} ; E t_{45}$ is the ventilation effectiveness of supply air angle of $45^{\circ} ; E t_{60}$ is the ventilation effectiveness of supply air angle of $60^{\circ} . \overline{E t_{15}}$ is selected as the base value. It is calculated that $\overline{E t_{15}}$ is $0.990, \overline{E t_{30}}$ is $0.917, \overline{E t_{45}}$ is $1.03, \overline{E t_{60}}$ is $1.03, \gamma_{30-15}$ is $0.926, \gamma_{45-15}$ is 1.04 , and $\gamma_{60-15}$ is 1.04. It depicts that, with a supply air angel of $45^{\circ}$, the ventilation effectiveness can achieve the highest value.

3.2.4. Return Air Outlet Position. The fitting formulae of the average ventilation effectiveness under different air outlet positions are as follows:

$$
\begin{aligned}
E t_{\mathrm{c}} & =0.932+0.133 h-0.035 h^{2}, \\
E t_{\text {oo }} & =0.96+0.142 h-0.04 h^{2}, \\
E t_{\text {uo }} & =1.004+0.149 h-0.04 h^{2}, \\
E t_{\text {us }} & =0.947+0.135 h-0.04 h^{2},
\end{aligned}
$$

where $E t_{c}$ is the ventilation effectiveness for the case of air outlet installed on the ceiling; $E t_{\mathrm{oo}}$ is the ventilation effectiveness of the outlet installed at the same level on the wall opposite to the supply air inlet; $E t_{\text {uo }}$ is the ventilation effectiveness for the air outlet located at the bottom of the wall opposite to the inlet; $E t_{\text {us }}$ is the ventilation effectiveness for the outlet located at the bottom of the same wall as the inlet. As shown in Figure 7, the change trends of $E t_{c}, E t_{\mathrm{oo}}$, $E t_{\mathrm{uo}}$, and $E t_{\mathrm{us}}$ are approximately consistent. And $\overline{E t_{\mathrm{c}}}$ is 0.991 , $\overline{E t_{\mathrm{oo}}}$ is $1.02, \overline{E t_{\mathrm{uo}}}$ is $1.07, \overline{E t_{\mathrm{us}}}$ is $1.01, \gamma_{\mathrm{oo}-\mathrm{c}}$ is $1.03, \gamma_{\mathrm{uo}-\mathrm{c}}$ is 1.08 , and $\gamma_{\text {us-c }}$ is 1.02 by calculation. The ventilation effectiveness can be obtained as the highest when the outlet is located under the opposite side.

\subsection{Effect of Supply Air Parameters on Effective Draft Temperature (EDT)}

3.3.1. Supply Air Temperature. Besides the ventilation effectiveness, effective draft temperature (EDT) is also a crucial factor for the thermal comfort evaluation. EDTs at three typical heights, namely, $0.1 \mathrm{~m}, 0.6 \mathrm{~m}$, and $1.1 \mathrm{~m}$, are calculated by (3) to obtain the frequency distribution under different supply air temperatures, as shown in Figure 8. It indicates that when the supply air temperature is $26.0^{\circ} \mathrm{C}, 62 \%$ of EDT is $0.4 \mathrm{~K}$ at the $0.1 \mathrm{~m}$ level, $78 \%$ of EDT is $0.5 \mathrm{~K}$ on the $0.6 \mathrm{~m}$ plane, and $68 \%$ of EDT is $1.1 \mathrm{~K}$ on the $1.1 \mathrm{~m}$ plane. When the supply air temperature is $27.0^{\circ} \mathrm{C}, 67 \%$ of EDT is $0 \mathrm{~K}$ on the $0.1 \mathrm{~m}$ plane, $76 \%$ of EDT is $0.8 \mathrm{~K}$ on the $0.6 \mathrm{~m}$ plane, and $65 \%$ of EDT is $0.9 \mathrm{~K}$ on the $1.1 \mathrm{~m}$ plane. When the temperature is $28.0^{\circ} \mathrm{C}, 71 \%$ of $\mathrm{EDT}$ is $0 \mathrm{~K}$ on the $0.1 \mathrm{~m}$ plane, $72 \% \mathrm{EDT}$ is $0.8 \mathrm{~K}$ on the $0.6 \mathrm{~m}$ plane, and $62 \% \mathrm{EDT}$ is $0.9 \mathrm{~K}$ on the $1.1 \mathrm{~m}$ plane. When the air supply temperature is $29.0^{\circ} \mathrm{C}$, the $0.1 \mathrm{~m}$ plane has $74 \% \mathrm{EDT}$ of $-0.09 \mathrm{~K}$, the $0.6 \mathrm{~m}$ plane has $63 \%$ EDT of $0.8 \mathrm{~K}$, and the $1.1 \mathrm{~m}$ plane has $59 \%$ EDT of $0.9 \mathrm{~K}$. It indicates that the EDT on the $0.1 \mathrm{~m}$ plane is closer to the neutral temperature when the supply air temperature is $27.0^{\circ} \mathrm{C}$ and $28.0^{\circ} \mathrm{C}$. And the percentage around the neutral temperature is higher when the supply air temperature is $28.0^{\circ} \mathrm{C}$. Hence, for the perspective of the EDT, the supply air temperature of $28.0^{\circ} \mathrm{C}$ shows the best effect.

It is reported that the EDT range that satisfies the occupant is between $-1.2 \mathrm{~K}$ and $1.2 \mathrm{~K}$. The average EDTs at four supply air temperatures are presented in Figure 9. It can be seen that the EDTs at $26-29^{\circ} \mathrm{C}$ are all within the satisfaction range. And the average EDTs among the occupied zone are $0.82 \mathrm{~K}\left(26^{\circ} \mathrm{C}\right), 0.68 \mathrm{~K}\left(27^{\circ} \mathrm{C}\right), 0.52 \mathrm{~K}$ $\left(28^{\circ} \mathrm{C}\right)$, and $0.37 \mathrm{~K}\left(29^{\circ} \mathrm{C}\right)$, respectively. Combining with the EDT frequency discussed results, $28.0^{\circ} \mathrm{C}$ is optimum under considering the impact of supply air temperature on EDT. 


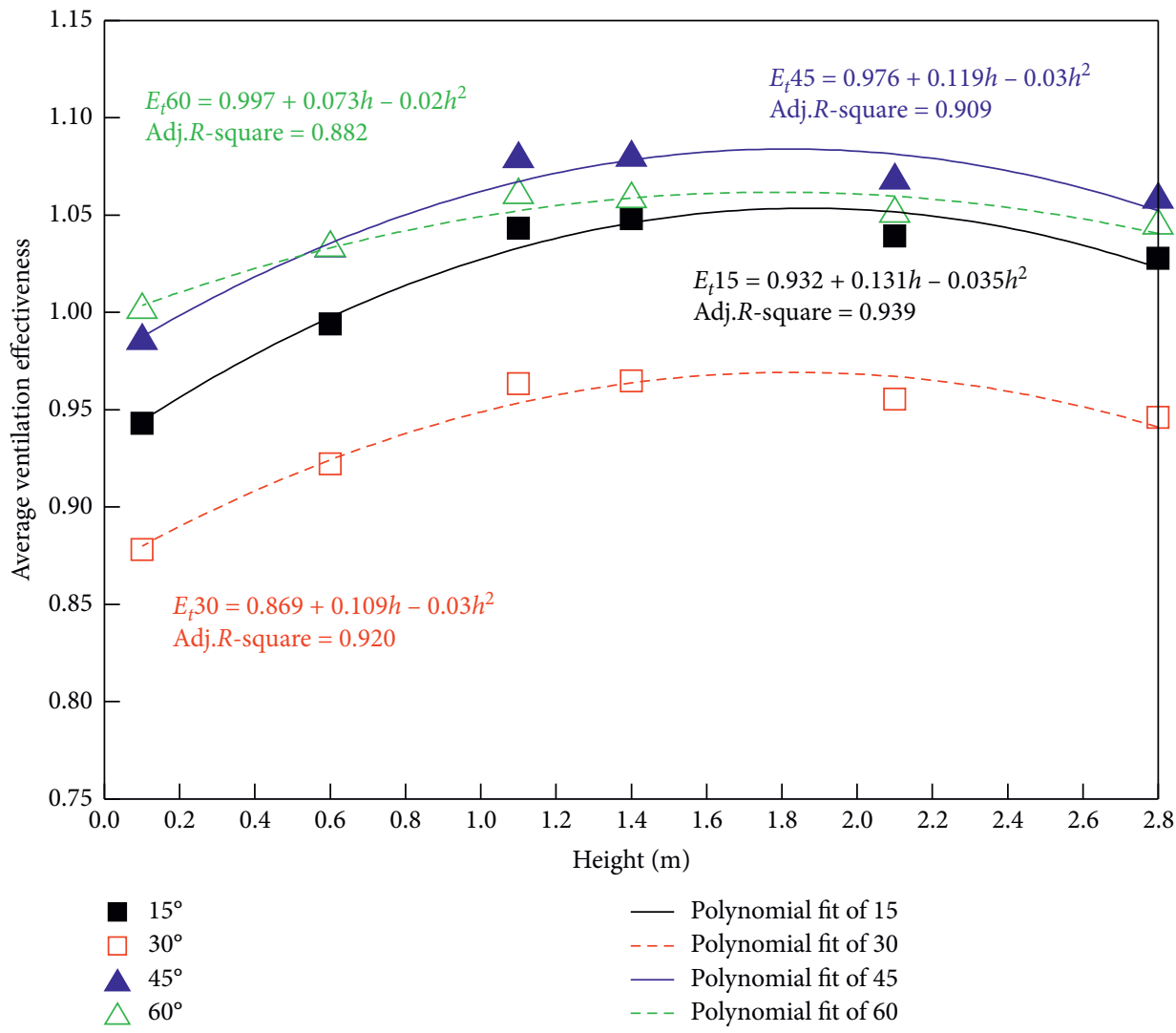

FIgURE 6: Average ventilation effectiveness at different supply air angles.

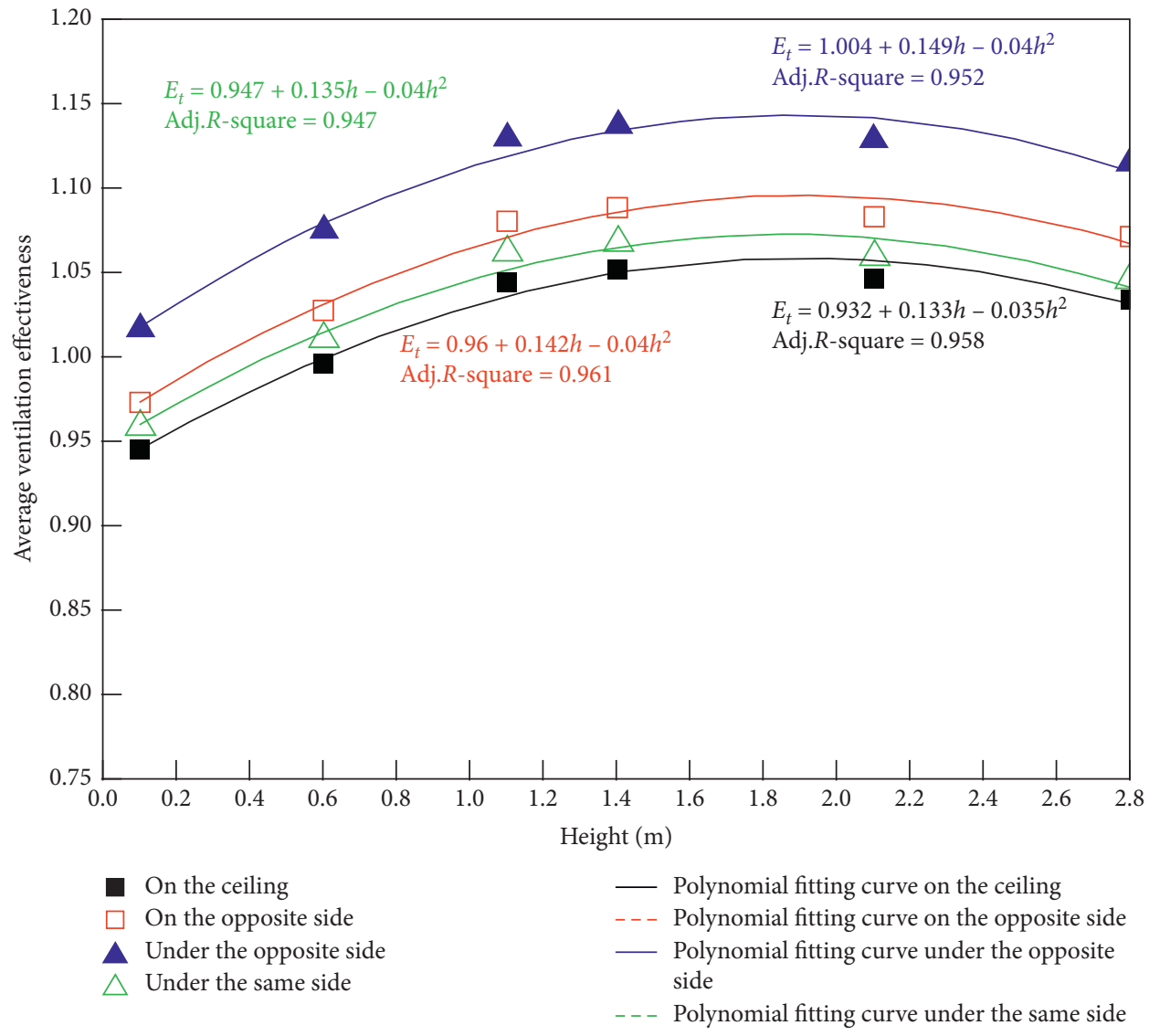

FIGURE 7: Average ventilation effectiveness at different air outlet positions. 


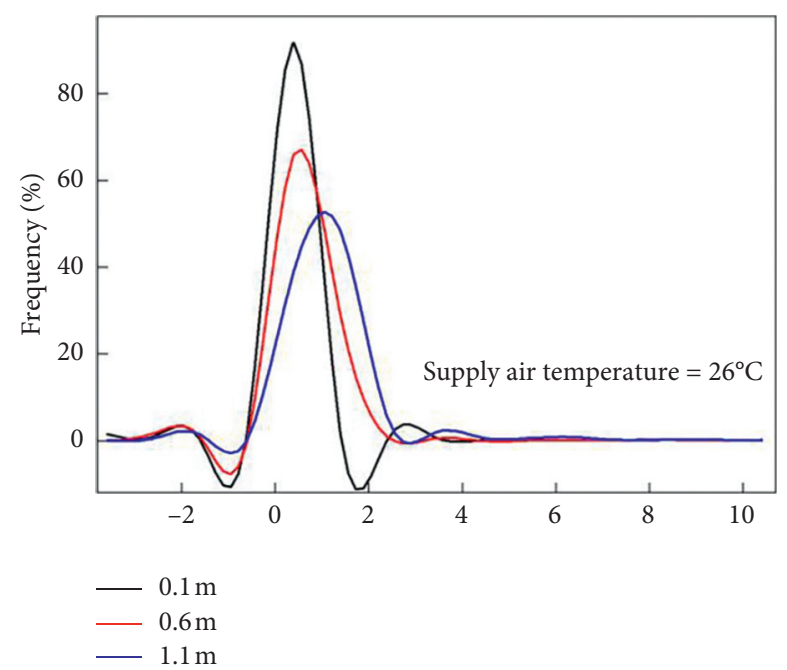

(a)

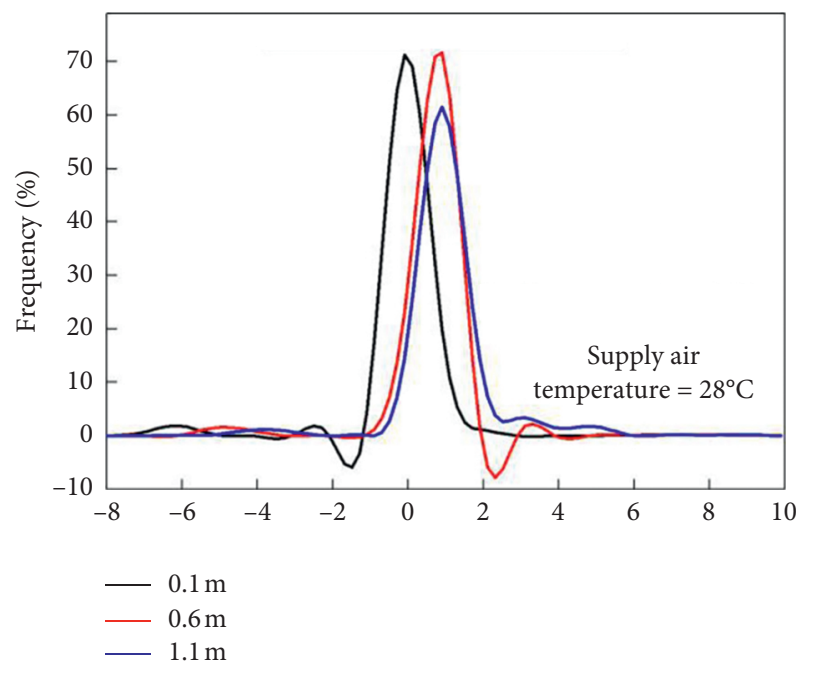

(c)

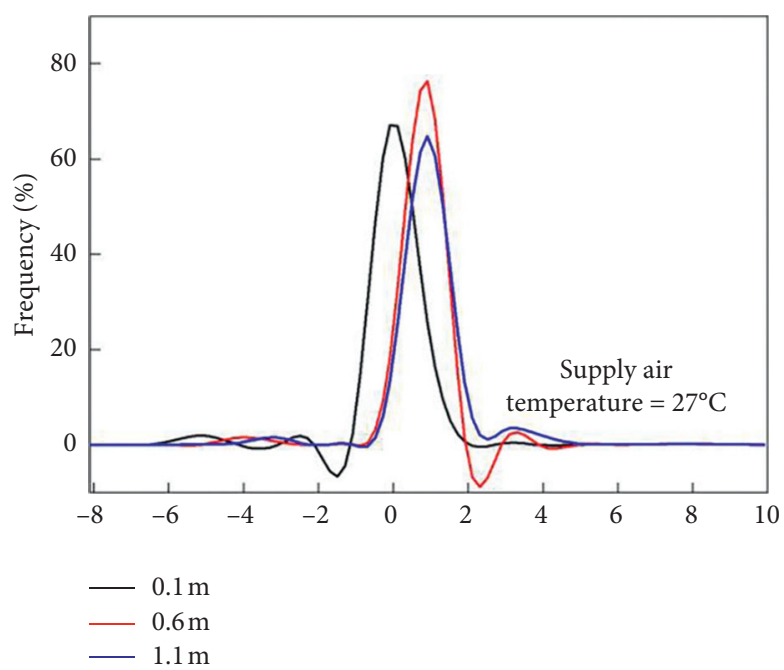

(b)

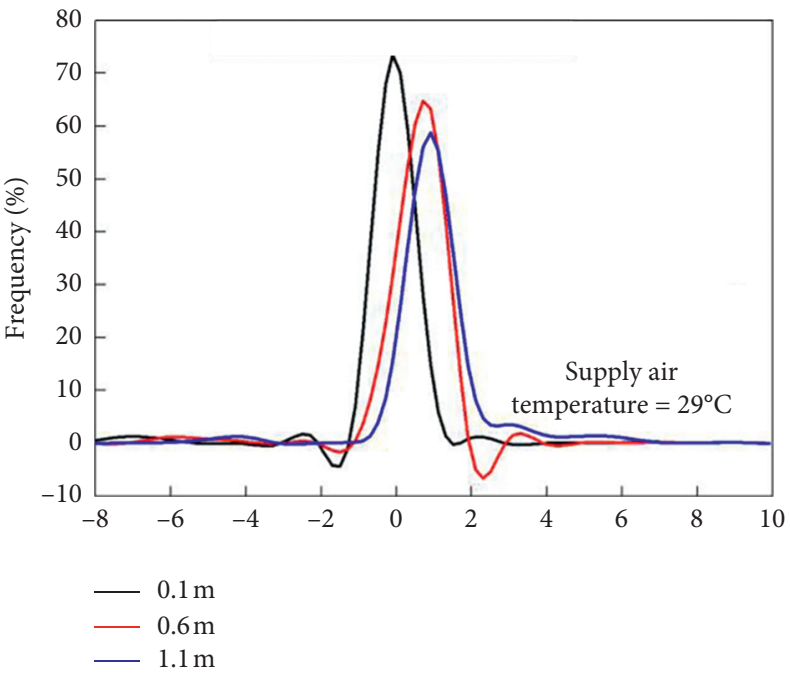

(d)

FIgURE 8: EDT frequency at different supply air temperatures.

3.3.2. Airflow Rate. The frequency distributions of EDT at different airflow rates are shown in Figure 10. It indicates that $85.3 \% \mathrm{EDT}$ is $0 \mathrm{~K}$ at the height of $0.1 \mathrm{~m}, 56.8 \% \mathrm{EDT}$ is $0.8 \mathrm{~K}$ at the height of $0.6 \mathrm{~m}$, and $65.5 \% \mathrm{EDT}$ is $1 \mathrm{~K}$ at the height of $1.1 \mathrm{~m}$ in the case of $10 \mathrm{ACH} .61 .45 \% \mathrm{EDT}$ is $0.8 \mathrm{~K}$ on the $0.1 \mathrm{~m}$ plane, $82.2 \% \mathrm{EDT}$ is $0 \mathrm{~K}$ on the $0.6 \mathrm{~m}$ plane, and $49.9 \% \mathrm{EDT}$ is $1 \mathrm{~K}$ on the $1.1 \mathrm{~m}$ plane in the case of $15 \mathrm{ACH}$. As for the case of $12 \mathrm{ACH}$, the highest frequency at $0.1 \mathrm{~m}, 0.6 \mathrm{~m}$, and $1.1 \mathrm{~m}$ is $71.6,67.8$, and $67.9 \%$ with EDT being $1 \mathrm{~K}$. Compared with other ACHs, the EDT frequency distribution close to $0 \mathrm{~K}$ at $0.1 \mathrm{~m}, 0.6 \mathrm{~m}$, and $1.1 \mathrm{~m}$ is relatively high when the airflow is $12 \mathrm{ACH}$. Therefore, the EDT at $12 \mathrm{ACH}$ has the highest percentage located in the comfort range among the occupied zones.

Meanwhile, Figure 11 shows that the EDTs among the occupied zones with airflow of $7-15 \mathrm{ACH}$ are all within the satisfaction range. However, the EDT of $10 \mathrm{ACH}$ is close to the upper limit of the satisfaction range. The average EDTs under different airflows among the occupied zones are
$0.87 \mathrm{~K}(7 \mathrm{ACH}), \quad 0.87 \mathrm{~K}(10 \mathrm{ACH}), 0.61 \mathrm{~K}(12 \mathrm{ACH})$, and $0.58 \mathrm{~K}(15 \mathrm{ACH})$, respectively. Hence, $12 \mathrm{ACH}$ is optimum under considering the impact of airflow on EDT combining with the EDT frequency.

3.3.3. Air Supply Angle. Similarly, to evaluate the impact of the air supply angle on the EDT, the frequency distribution at different supply air angles is presented in Figure 12. It can be seen that most of the EDTs at four air supply angles are within the comfort interval. When the air supply angle is $60^{\circ}$, the proportions located in comfort zone at $0.1 \mathrm{~m}, 0.6 \mathrm{~m}$, and $1.1 \mathrm{~m}$ are $95 \%, 97 \%$, and $90 \%$, respectively, which gets the highest among the four air supply angles. Therefore, from the viewpoint of the EDT frequency distribution, it is optimal when the supply air angle is $60^{\circ}$.

In Figure 13, the EDTs of the occupied area with supply angles of $45^{\circ}$ and $60^{\circ}$ are within the satisfaction range while those of $15^{\circ}$ and $30^{\circ}$ are beyond the upper limit of the 


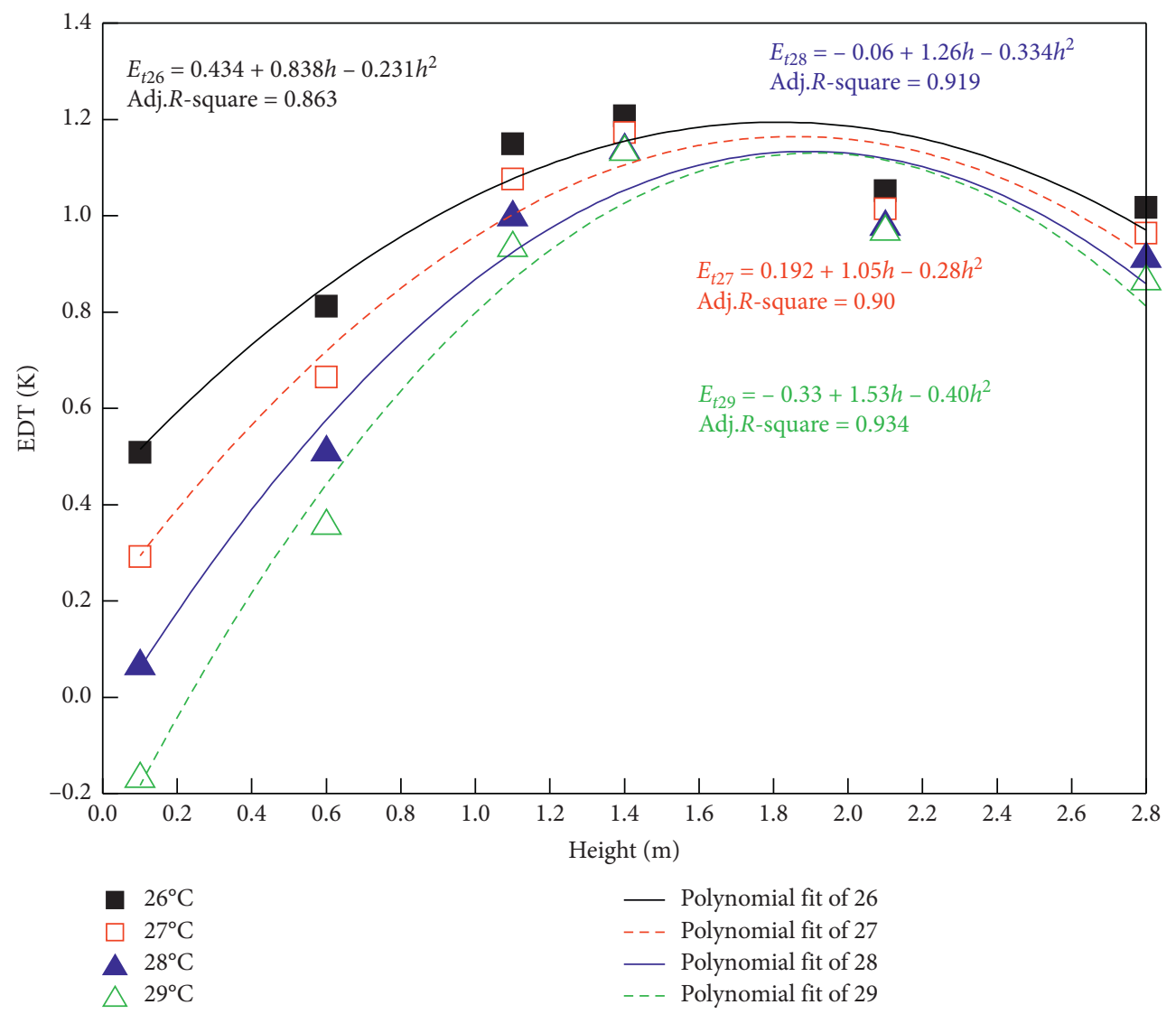

FIgURE 9: Average EDT at different supply air temperatures.
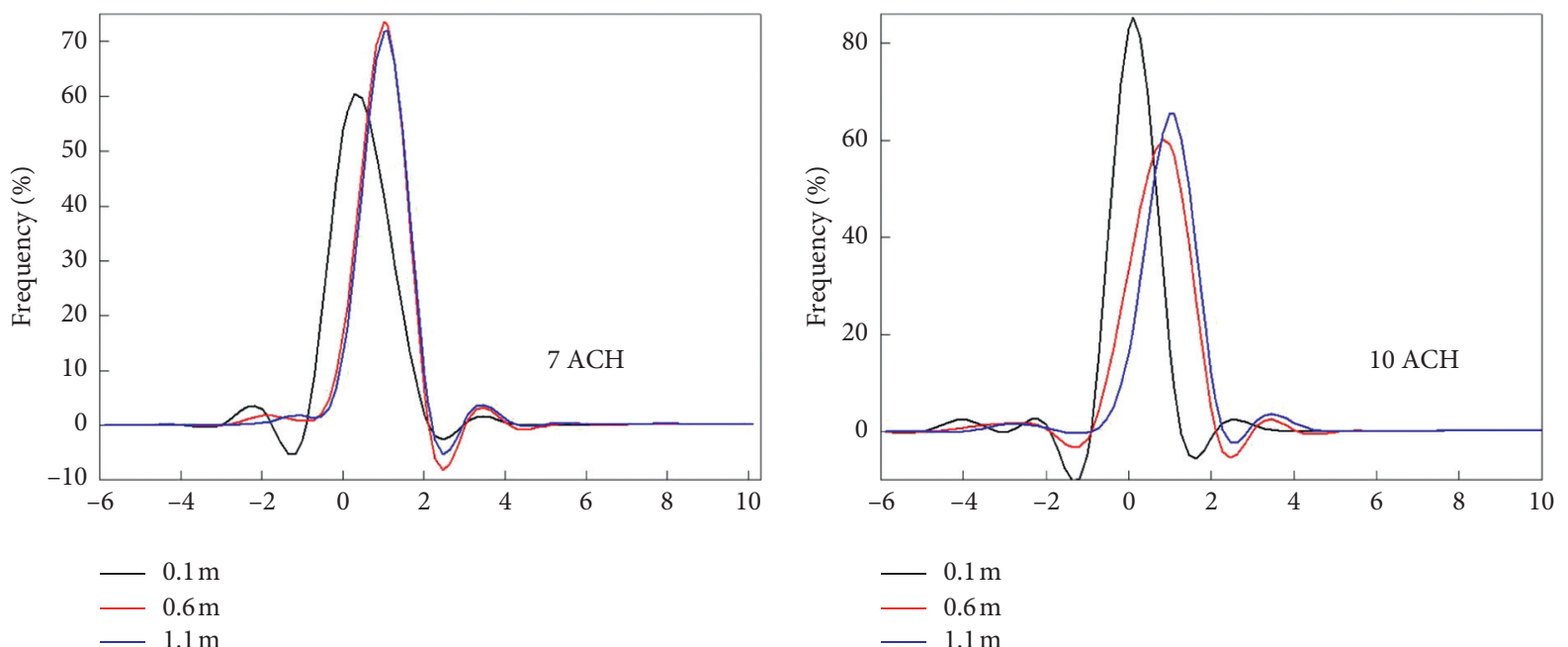

(a)

(b)

Figure 10: Continued. 


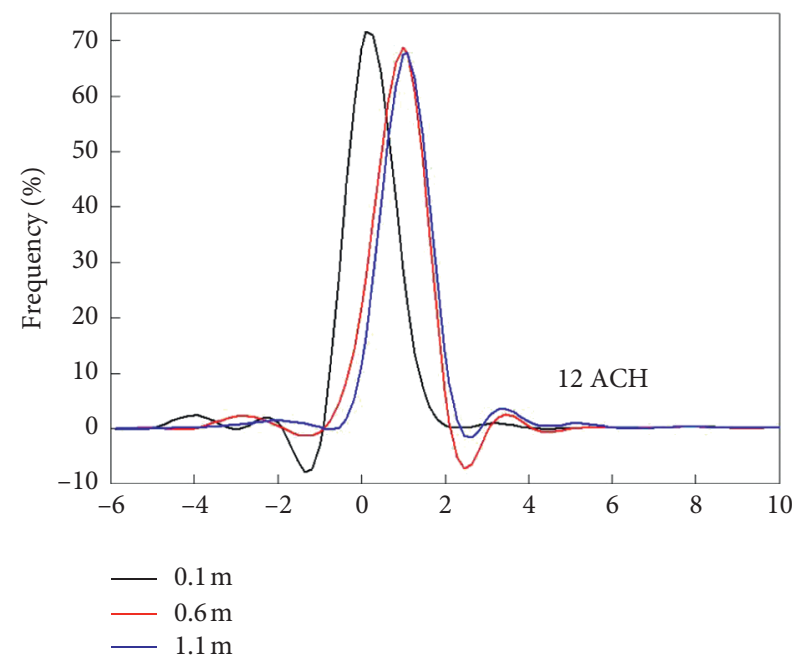

(c)

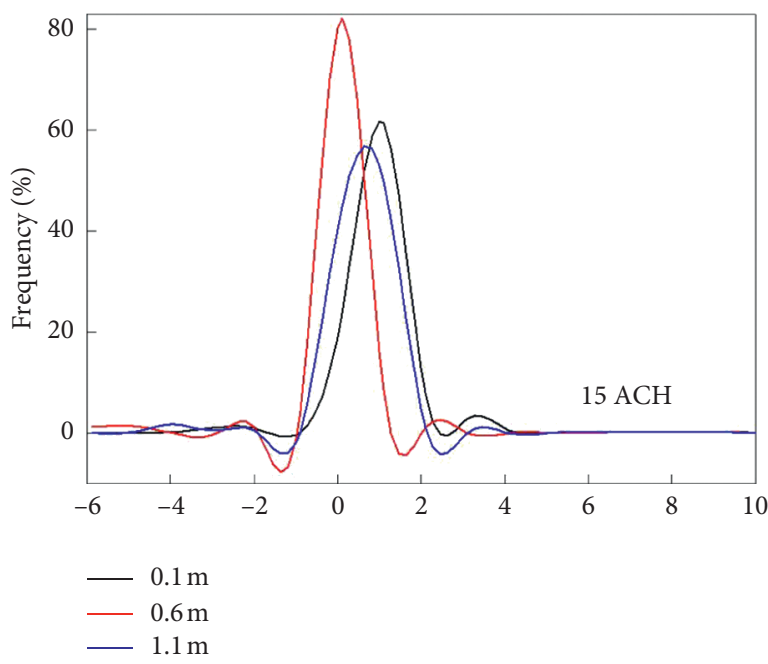

(d)

Figure 10: EDT frequency at different airflow rates $(\mathrm{ACH})$.

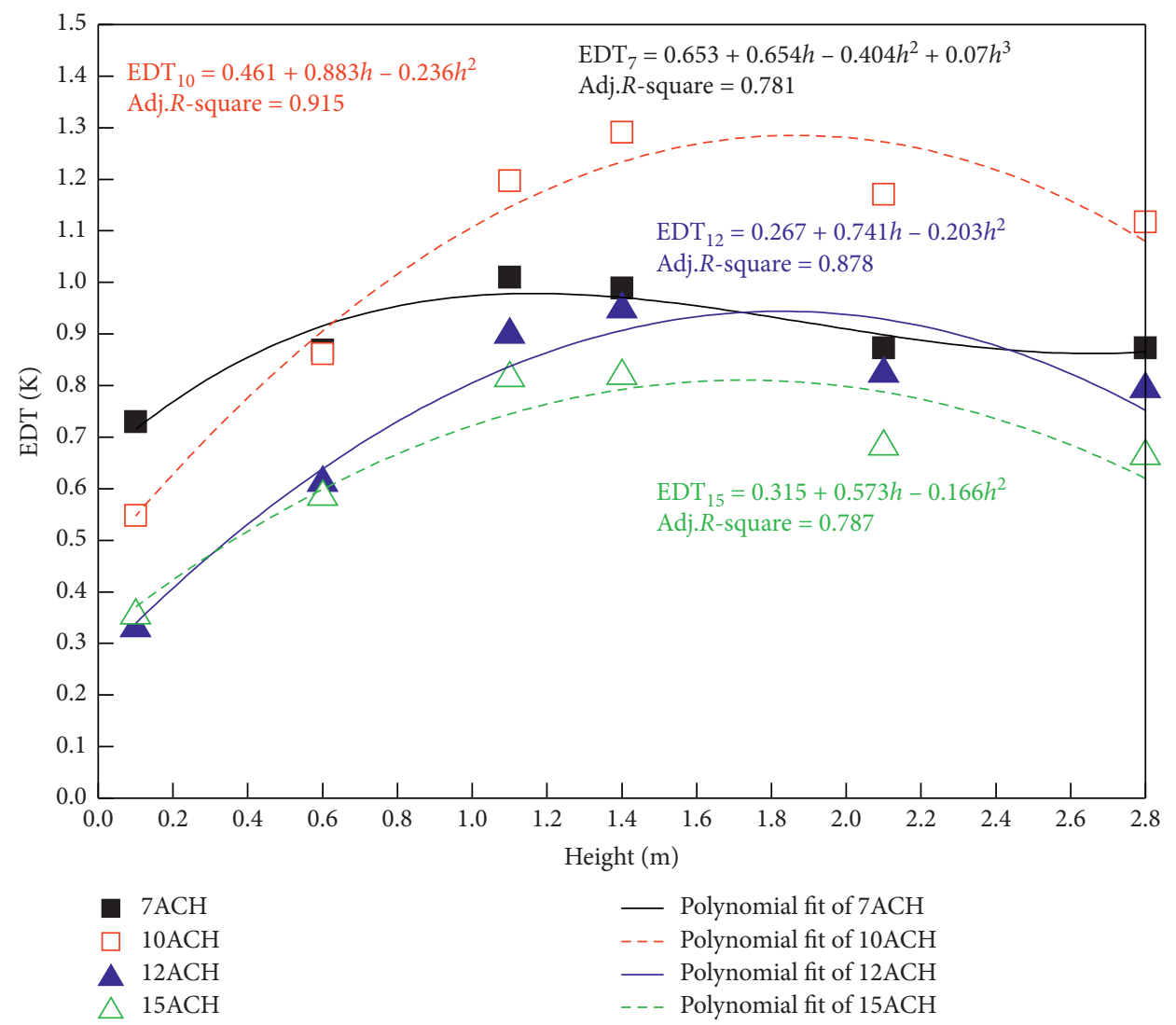

Figure 11: Average EDT at different airflow rates (ACH).

satisfaction range. Meanwhile, the average EDTs under different angles among the occupied zones are $1.88 \mathrm{~K}\left(15^{\circ}\right)$, $1.44 \mathrm{~K}\left(30^{\circ}\right), 0.67 \mathrm{~K}\left(45^{\circ}\right)$, and $-0.91 \mathrm{~K}\left(60^{\circ}\right)$, respectively. Although the average EDT at the supply angle of $45^{\circ}$ is closer to $0 \mathrm{~K}$ relative to $60^{\circ}$, the proportions located within the comfort zone at $60^{\circ}$ is the highest according to the frequency distribution. Hence, $60^{\circ}$ is optimum under considering the impact of supply angle on EDT.

3.3.4. Return Air Outlet Position. The frequency statistics of the EDTs in the occupied zone are calculated under discussed return air outlet positions. Figure 14 

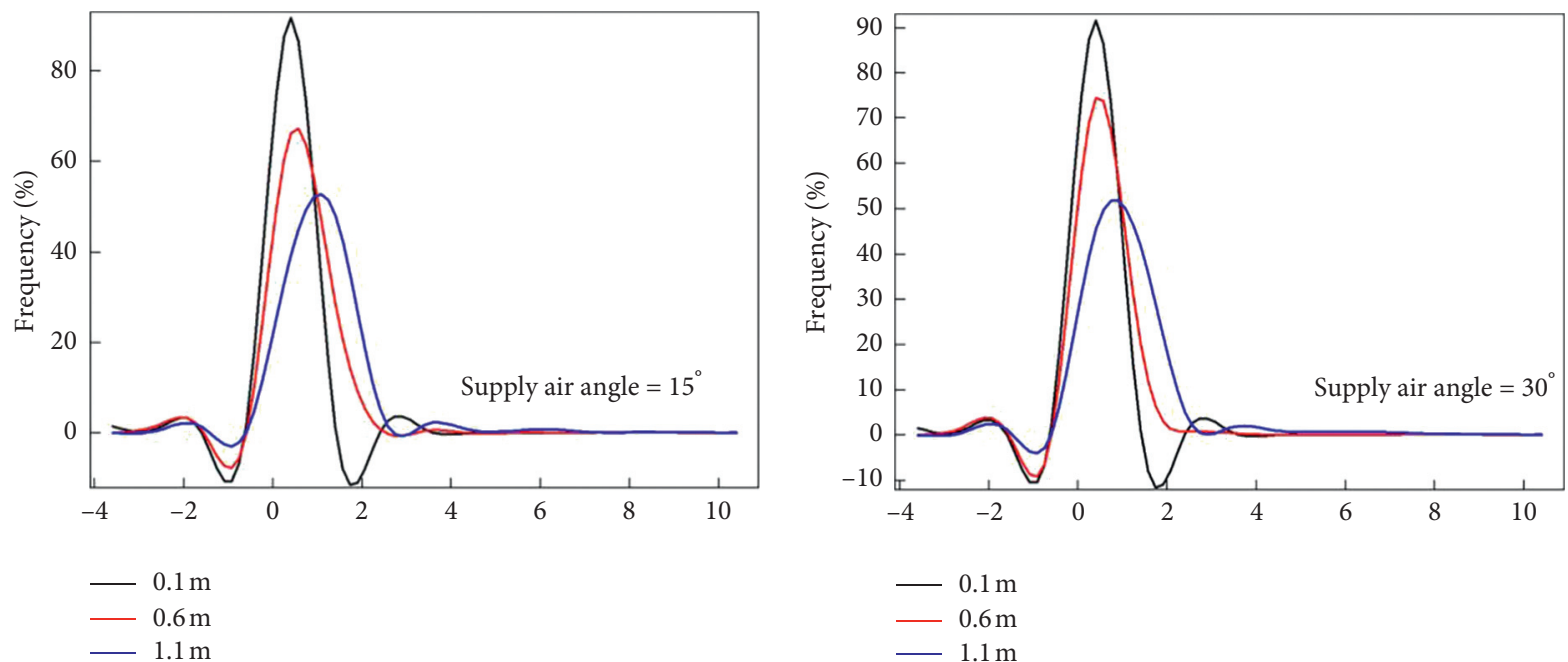

(a)

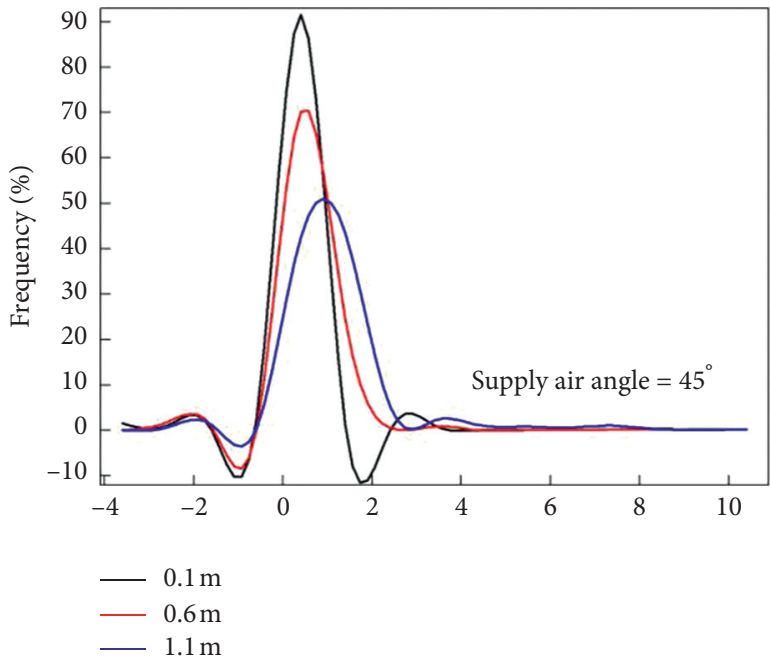

(b)

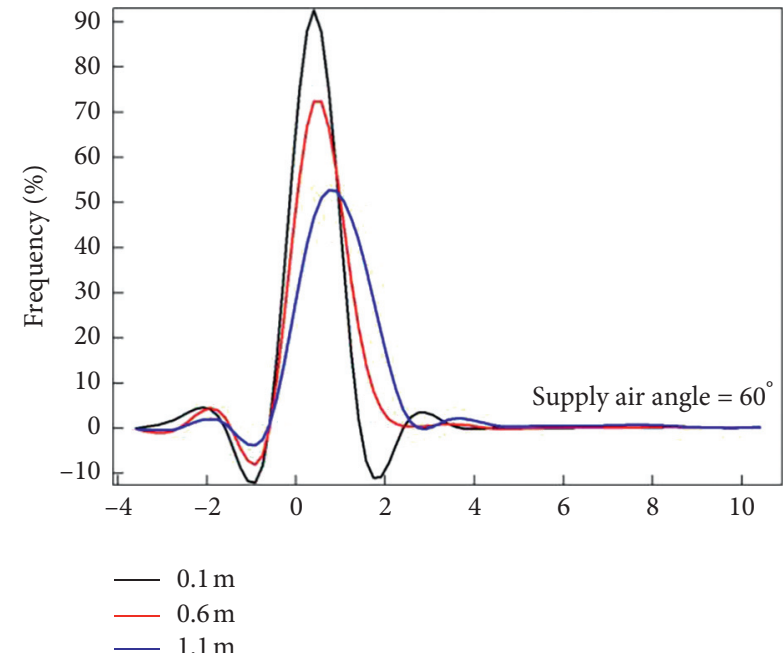

(c)

(d)

Figure 12: EDT frequency at different supply air angles.

demonstrates that more than $86 \%$ of the EDTs under the four return air outlets are within the comfort range. And the proportions within the comfort range of the three return air outlet layouts, namely, on the ceiling, right on the opposite wall, and at the lower level on the opposite wall, are the same. When the position of the return air outlet is at the lower level on the same wall, $95 \%$ of the EDTs belong to the comfort range, so the effect of EDT is the best when the return air outlet is on the same wall beneath the air supply inlet.

As presented in Figure 15, it can be seen that the EDTs among the occupied zones under four outlet locations are all within the satisfaction range. Nevertheless, the EDT with the outlet under the opposite side is close to the upper limit of the satisfaction range. Meanwhile, the average EDTs under different return air outlets among the occupied zones are $0.62 \mathrm{~K}$ (on the ceiling), $0.74 \mathrm{~K}$ (on the opposite side), $0.89 \mathrm{~K}$ (under the opposite side), and $0.72 \mathrm{~K}$ (under the same side), respectively. Because the EDT located in the comfort zone is the highest when the outlets are installed under the same side with the inlets, the position of the return air outlet is located at the same wall but at a lower level as the air supply inlet can reach the best performance. 

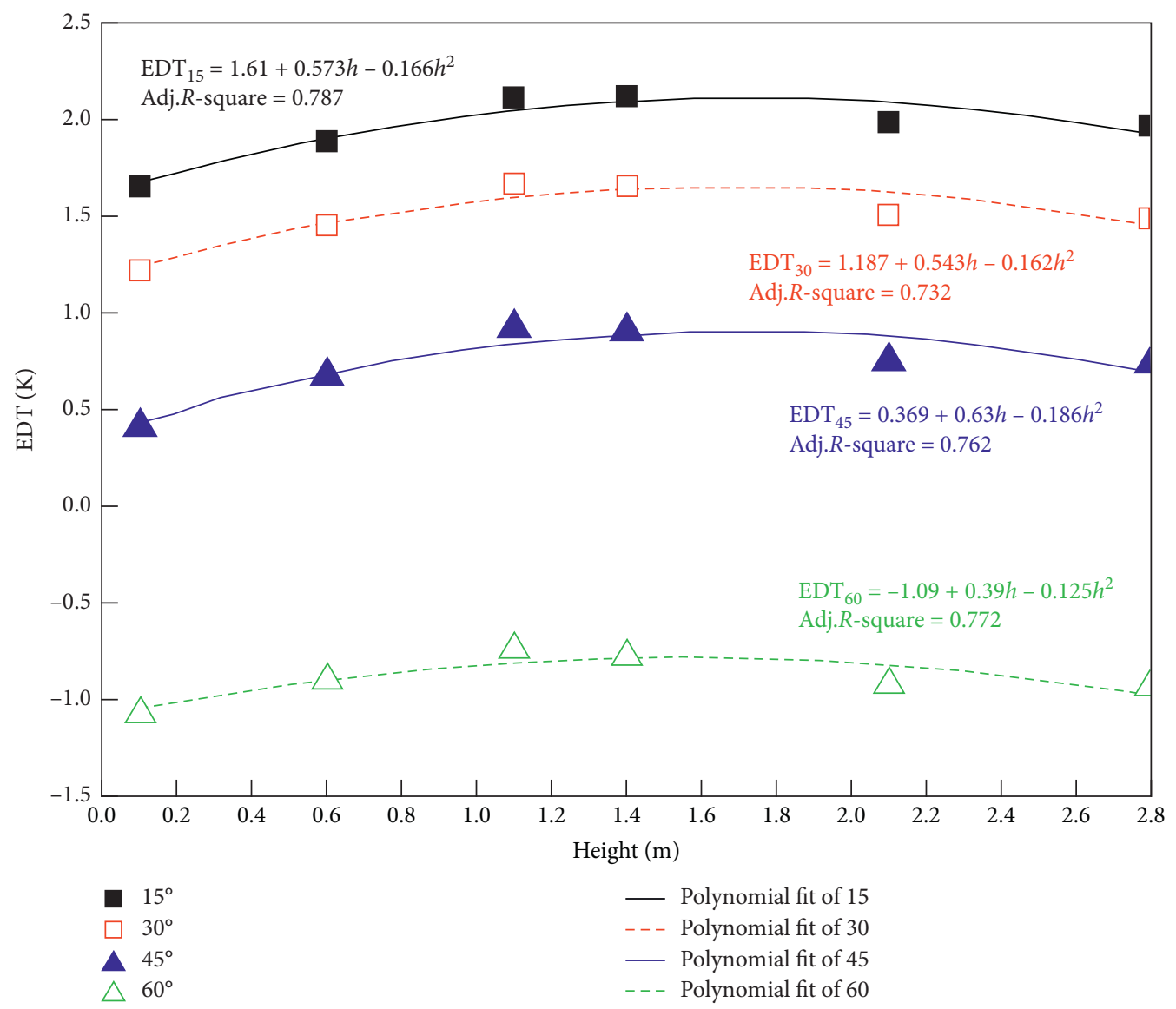

FIGURE 13: Average EDT at different supply air angles.

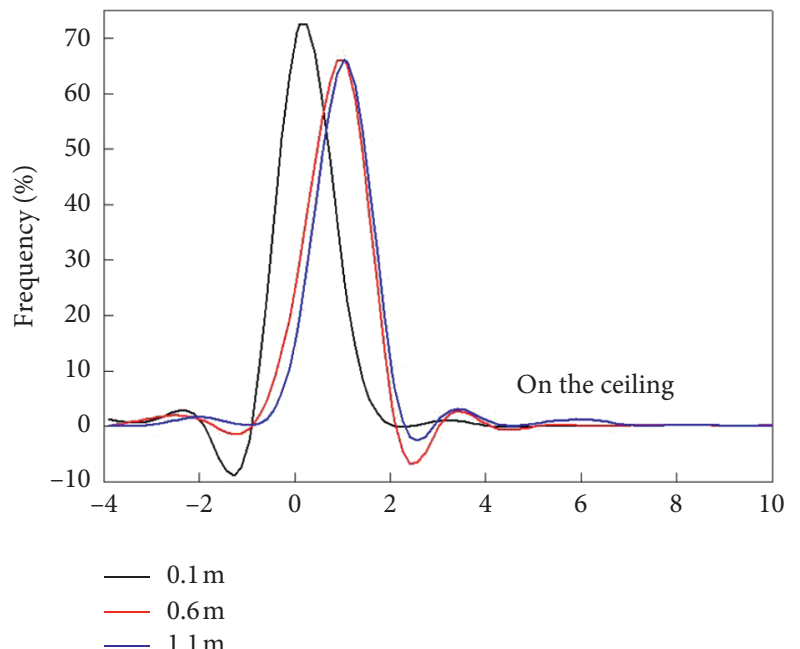

(a)

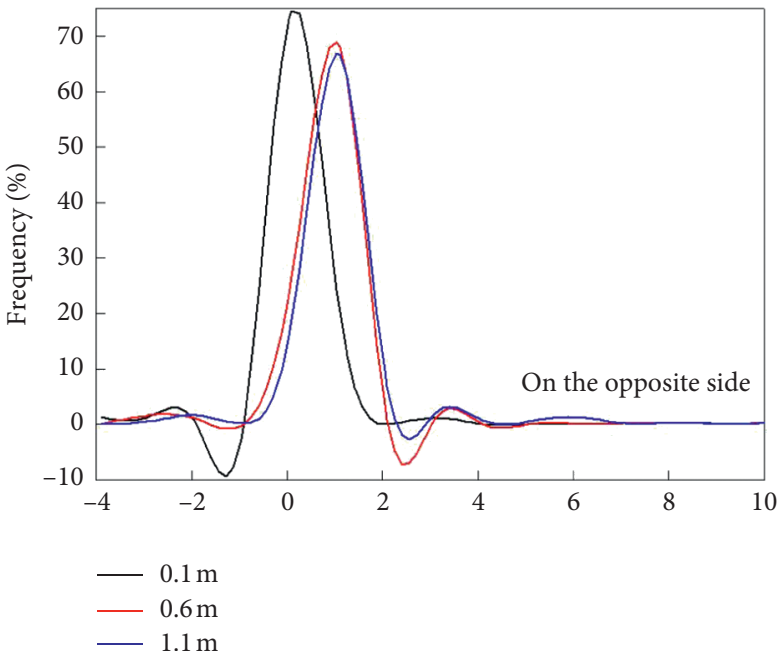

(b)

Figure 14: Continued. 


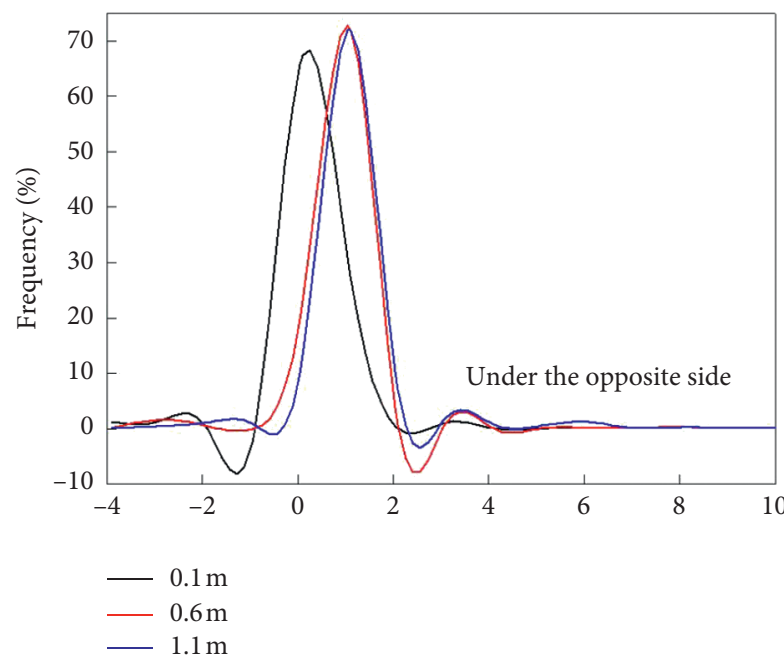

(c)

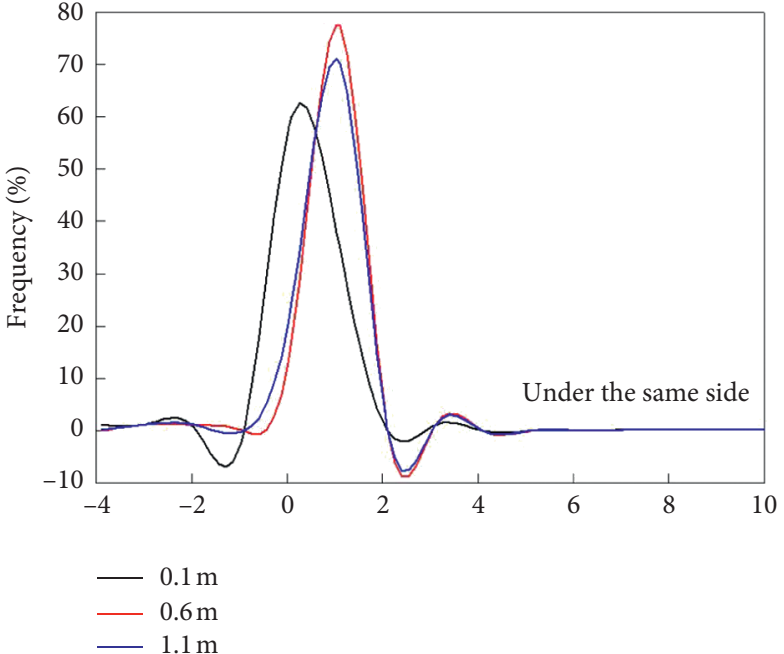

(d)

FIgURE 14: EDT frequency for different air outlet positions.

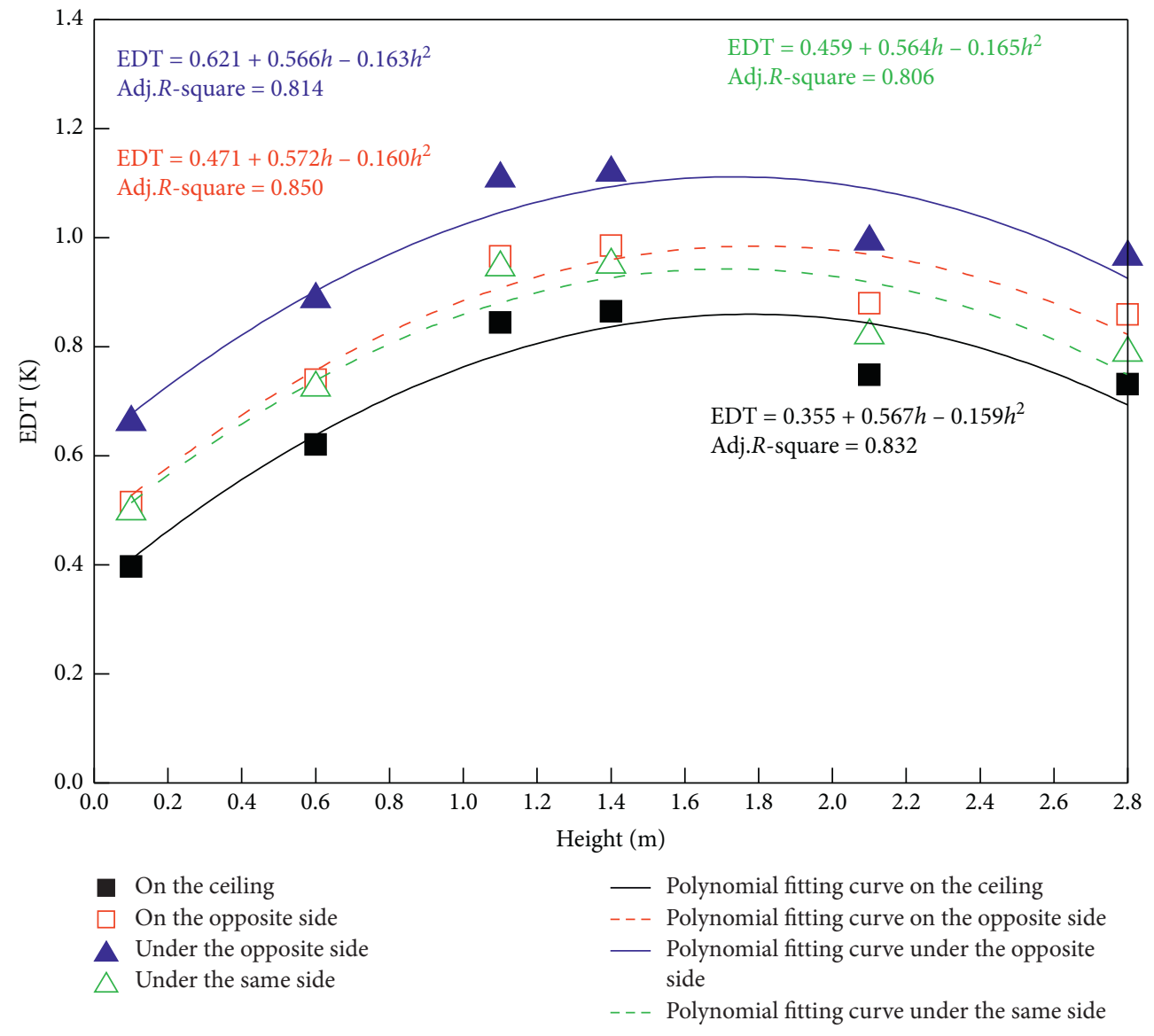

FIgURE 15: Average EDT at different air outlet positions. 


\section{Conclusion}

The optimal heating parameters of stratum ventilation were explored through experimental and numerical approaches by comparing the differences of impacts among various parameters on the aspects of ventilation performance and thermal comfort. The main conclusions are presented as below:

(1) The ventilation effectiveness was higher with $26^{\circ} \mathrm{C}$ of the supply air temperature, $7 \mathrm{ACH}$ of the airflow rate, and $45^{\circ}$ of the air supply angle. The energy utilization can achieve the highest with the above supply air parameters. Moreover, by calculating and comparing the ventilation effectiveness under various return air outlets, it indicated that the value of ventilation effectiveness reached its highest when the return air outlet is located at $0.5 \mathrm{~m}$ above the floor on the wall opposite to the air inlet.

(2) The EDT range among the occupied zones was between 0.65 and $1.02 \mathrm{~K}$ at the supply air temperature of $28^{\circ} \mathrm{C}$, which is the closest to $0 \mathrm{~K}$ compared with that at other supply air temperatures. Meanwhile, the EDTs with the air supply angle of $60^{\circ}$ and airflow of $12 \mathrm{ACH}$ are closer to the neutral temperature. The EDT under the return air outlet at the bottom of the same wall as the air supply inlet was in the range of $0.53-0.75 \mathrm{~K}$, which is the closest to the comfort temperature. Hence, the best supply air parameters are $28^{\circ} \mathrm{C}, 12 \mathrm{ACH}, 60^{\circ}$ and return air outlet at the bottom of the same wall as the air supply inlet under stratum ventilation for obtaining the best thermal comfort.

The related conclusions obtained from this research provide the theoretical basis for stratum ventilation design and promote its heating application in Southern China.

\section{Data Availability}

The data used to support the findings of this study are available from the corresponding author upon request.

\section{Conflicts of Interest}

The authors declare that there are no conflicts of interest regarding the publication of this paper.

\section{Acknowledgments}

This research was supported by the Zhejiang Provincial Natural Science Foundation of China under Grant no. LGF21E080007.

\section{References}

[1] X. Song, G. Liang, C. Li, and W. Chen, "Electricity consumption prediction for xinjiang electric energy replacement," Mathematical Problems in Engineering, vol. 2019, Article ID 3262591, 11 pages, 2019.
[2] Y. Zhang, Y. Liu, and Y. Liu, “A hybrid dynamical modelling and control approach for energy saving of central air conditioning," Mathematical Problems in Engineering, vol. 2018, Article ID 6389438, 12 pages, 2018.

[3] Z. Zhao, N. Yu, Y. Tao, and H. Zhang, "Data analysis and modeling of chilled water loops in air conditioning systems," Mathematical Problems in Engineering, vol. 2017, Article ID 9040242, 16 pages, 2017.

[4] J. Shang, X. Hu, F. Gu, Di Wang, and S. Yu, "Improvement schemes for indoor mobile location estimation: a survey," Mathematical Problems in Engineering, vol. 2015, Article ID 397298, 32 pages, 2015.

[5] Z. Lin, T. T. Chow, and C. F. Tsang, "Stratum ventilation? a conceptual introduction," in Proceedings of the 10th International Conference on Indoor Air Quality and Climate, Beijing, China, September 2005.

[6] M. L. Fong, Z. Lin, K. F. Fong, T. T. Chow, and T. Yao, "Evaluation of thermal comfort conditions in a classroom with three ventilation methods," Indoor Air, vol. 21, no. 3, pp. 231-239, 2011.

[7] S. Zhang, Y. Cheng, Z. Fang, C. Huan, and Z. Lin, "Optimization of room air temperature in stratum-ventilated rooms for both thermal comfort and energy saving," Applied Energy, vol. 204, pp. 420-431, 2017.

[8] Y. Cheng, Z. Lin, and A. M. L. Fong, "Effects of temperature and supply airflow rate on thermal comfort in a stratumventilated room," Building and Environment, vol. 92, pp. 269-277, 2015.

[9] L. Tian, Z. Lin, and Q. Wang, "Comparison of gaseous contaminant diffusion under stratum ventilation and under displacement ventilation," Building and Environment, vol. 45, no. 9, pp. 2035-2046, 2010.

[10] S. Zhang, Y. Cheng, M. O. Oladokun, and Z. Lin, "Subzone control method of stratum ventilation for thermal comfort improvement," Building and Environment, vol. 149, pp. 3947, 2019.

[11] M. L. Fong, V. Hanby, R. Greenough, Z. Lin, and Y. Cheng, "Acceptance of thermal conditions and energy use of three ventilation strategies with six exhaust configurations for the classroom," Building and Environment, vol. 94, pp. 606-619, 2015.

[12] H. Zhao, Z. Liu, and Z. Zuo, "Numerical simulation of indoor thermal environment effected by air supply temperature and grille angle on stratum ventilation in a typical office," Procedia Engineering, vol. 121, pp. 779-784, 2015.

[13] T. Yao and Z. Lin, "An experimental and numerical study on the effect of air terminal layout on the performance of stratum ventilation," Building and Environment, vol. 82, pp. 75-86, 2014.

[14] Y. Cheng and Z. Lin, "Experimental study of airflow characteristics of stratum ventilation in a multi-occupant room with comparison to mixing ventilation and displacement ventilation," Indoor Air, vol. 25, no. 6, pp. 662-671, 2015.

[15] L. Han, X. Chang, X. Kong, L. Zhang, and L. Wang, "A comparative experimental investigation on radiant floor heating system and stratum ventilation," Sustainable Cities and Society, vol. 52, Article ID 101823, 2020.

[16] J. Liu and Z. Lin, "Energy and exergy performances of floor, ceiling, wall radiator and stratum ventilation heating systems for residential buildings," Energy and Buildings, vol. 220, Article ID 110046, 2020.

[17] S. Zhang, Z. Lin, Z. Ai, C. Huan, Y. Cheng, and F. Wang, "Multi-criteria performance optimization for operation of 
stratum ventilation under heating mode," Applied Energy, vol. 239, pp. 969-980, 2019.

[18] X. Kong, C. Xi, H. Li, and Z. Lin, "Multi-parameter performance optimization for whole year operation of stratum ventilation in offices," Applied Energy, vol. 268, Article ID 114966, 2020.

[19] X. Kong, C. Xi, H. Li, and Z. Lin, “A comparative experimental study on the performance of mixing ventilation and stratum ventilation for space heating," Building and Environment, vol. 157, pp. 34-46, 2019.

[20] Y. Cheng and Z. Lin, "Experimental investigation into the interaction between the human body and room airflow and its effect on thermal comfort under stratum ventilation," Indoor Air, vol. 26, no. 2, pp. 274-285, 2016.

[21] S. J. Kline and F. A. McClintock, "Describing uncertainties in single-sample experiments," Mechanical Engineering, vol. 75, no. 1, pp. 3-8, 1953.

[22] J. Qian, J. P. Lu, S. L. Hui, and Y. J. Ma, D. Y. Li, Dynamic analysis and CFD numerical simulation on backpressure filling system," Mathematical Problems in Engineering, vol. 2015, Article ID 160641, 8 pages, 2015.

[23] Y. Shi, S. Ren, M. Cai, and W. Xu, "Modelling and simulation of volume controlled mechanical ventilation system," Mathematical Problems in Engineering, vol. 2014, Article ID 271053, 7 pages, 2014.

[24] Y. Li, G. Sun, and X. Wang, "Temperature field-wind velocity field optimum control of greenhouse environment based on CFD model," Mathematical Problems in Engineering, vol. 2014, Article ID 949128, 9 pages, 2014.

[25] Y.-L. Yu, Y.-T. Chao, L.-C. Lee, J.-Y. Yen, and Y.-C. Fan, "A novel soundproof ventilation plant design with high performance and no energy consumption," Mathematical Problems in Engineering, vol. 2015, Article ID 496748, 10 pages, 2015.

[26] C. Zheng, S. You, H. Zhang et al., "Comparison of airconditioning systems with bottom-supply and side-supply modes in a typical office room," Applied Energy, vol. 227, pp. 304-311, 2018.

[27] Y. Cheng, "Experimental and numerical study of air distribution characteristics and thermal environment under stratum ventilation," Ph. D. Dissertation, University of Hong Kong, Hong Kong, China, 2015.

[28] ANSYS Inc, ANSYS Fluent Theory Guide, ANSYS Inc, Canonsburg, PA, USA, 2013.

[29] H. Manz and T. Frank, "Analysis of thermal comfort near cold vertical surfaces by means of computational fluid dynamics," Indoor and Built Environment, vol. 13, no. 3, pp. 233-242, 2004.

[30] T. Karimipanaha, H. B. Awbi, M. Sandberg, and C. Blomqvistc, "Investigation of air quality, comfort parameters and effectiveness for two floor-level air supply systems in classrooms," Building and Environment, vol. 42, no. 2, pp. 647-655, 2007.

[31] Y. Xiang and G. Zhou, "Thermal performance of a windowbased cooling unit using phase change materials combined with night ventilation," Energy and Buildings, vol. 108, pp. 267-278, 2015.

[32] Z. Lin, "Effective draft temperature for evaluating the performance of stratum ventilation," Building and Environment, vol. 46, pp. 1843-1850, 2011.

[33] D. N. Moriasi, J. G. Arnold, M. W. Van Liew, R. Binger, R. D. Harmel, and T. L. Veith, "Model evaluation guidelines for systematic quantification of accuracy in watershed simulations," Transactions of the ASABE, vol. 50, no. 3, pp. 885-900, 2007.

[34] J. L. Fleiss, "Measuring nominal scale agreement among many raters," Psychological Bulletin, vol. 76, no. 5, pp. 378-382, 1971. 